\title{
Risk and Valuation of Collateralized Debt Obligations
}

\author{
Darrell Duffie and Nicolae Gârleanu
}

\begin{abstract}
In this discussion of risk analysis and market valuation of collateralized debt obligations, we illustrate the effects of correlation and prioritization on valuation and discuss the "diversity score" (a measure of the risk of the CDO collateral pool that has been used for CDO risk analysis by rating agencies) in a simple jump diffusion setting for correlated default intensities.
\end{abstract}

$\mathcal{A}$ collateralized debt obligation is an assetbacked security whose underlying collateral is typically a portfolio of (corporate or sovereign) bonds or bank loans. ACDO cash flow structure allocates interest income and principal repayments from a collateral pool of different debt instruments to a prioritized collection of CDO securities, which we call "tranches." Although many forms of prioritization exist, a standard prioritization scheme is simple subordination: Senior CDO notes are paid before mezzanine and lower subordinated notes are paid, with any residual cash flow paid to an equity piece. We provide some examples of prioritization later in this article.

A cash flow CDO is one for which the collateral portfolio is not subjected to active trading by the CDO manager, which implies that the uncertainty regarding interest and principal payments to the $\mathrm{CDO}$ tranches is induced mainly by the number and timing of defaults of the collateral securities. A market-value $\mathrm{CDO}$ is one in which the $\mathrm{CDO}$ tranches receive payments based essentially on the markedto-market returns of the collateral pool, as determined largely by the trading performance of the $\mathrm{CDO}$ manager. We concentrate here on cash flow CDOs, thus avoiding an analysis of the trading behavior of CDO managers.

A generic example of the contractual relationships involved in a CDO is shown in Figure 1. The collateral manager is charged with the selection and purchase of collateral assets for the CDO special-purpose vehicle (SPV). The trustee of the CDO is responsible for monitoring the contractual provisions of the CDO. Our analysis assumes perfect adherence to these contractual provisions. The

Darrell Duffie is James I. Miller Professor of Finance and Nicolae Gârleanu is a graduate student at the Stanford University Graduate School of Business. main issue we address is the impact of the joint distribution of default risk of the underlying collateral securities on the risk and valuation of the CDO tranches. We are also interested in the efficacy of alternative computational methods and the role of "diversity scores," a measure of the risk of the CDO collateral pool that has been used for CDO risk analysis by rating agencies.

\section{CDO Design and Valuation}

In perfect capital markets, CDOs would serve no purpose; the costs of constructing and marketing a CDO would inhibit its creation. In practice, CDOs address some important market imperfections. First, banks and certain other financial institutions have regulatory capital requirements that make valuable the securitizing and selling of some portion of their assets; the value lies in reducing the amount of (expensive) regulatory capital they must hold. Second, individual bonds or loans may be illiquid, which reduces their market values; if securitization improves their liquidity, it raises the total valuation to the issuer of the CDO structure.

In light of these market imperfections, at least two classes of CDOs are popular. The balance sheet $\mathrm{CDO}$, typically in the form of a collateralized loan obligation (CLO), is designed to remove loans from the balance sheets of banks, thereby providing capital relief and perhaps also increasing the valuation of the assets through an increase in liquidity. ${ }^{1} \mathrm{An}$ arbitrage $\mathrm{CDO}$, often underwritten by an investment bank, is designed to capture some fraction of the likely difference between the total cost of acquiring collateral assets in the secondary market and the value received from management fees and the sale of the associated CDO structure. Balance sheet CDOs are normally of the cash flow type. Arbitrage CDOs may be collateralized bond obligations and have either cash flow or market-value structures. 


\section{Figure 1. Typical CDO Contractual Relationships}

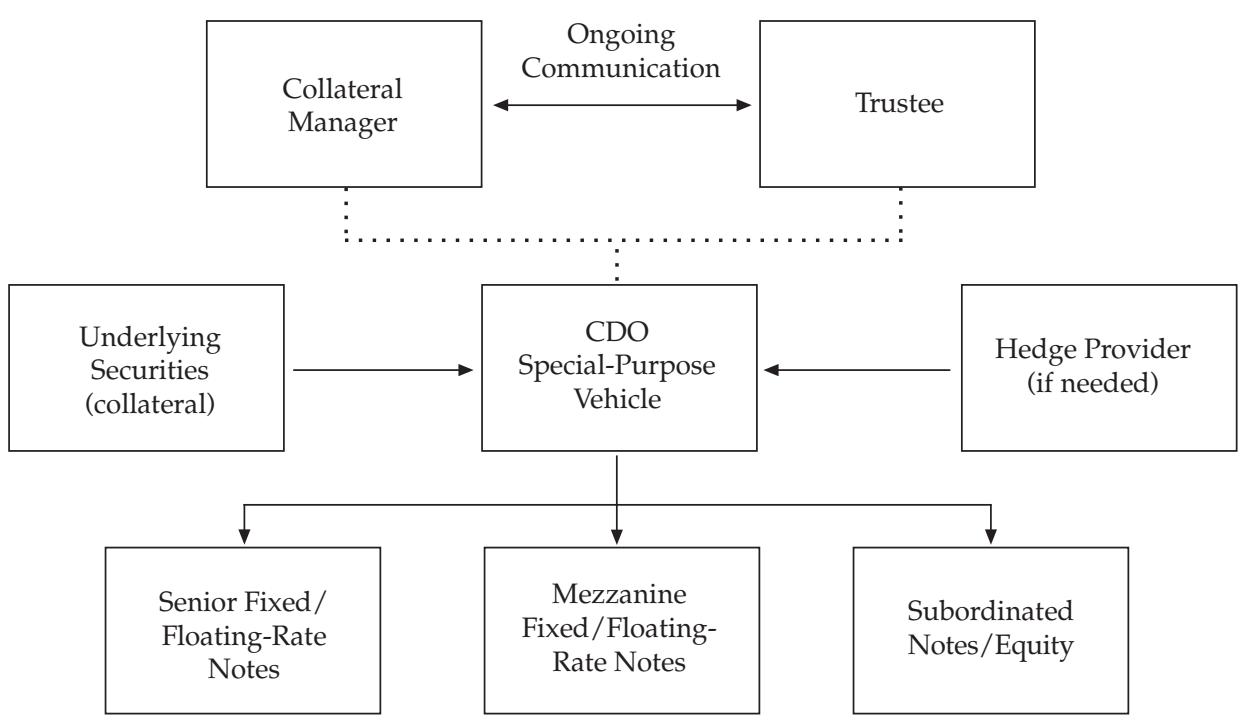

Source: Morgan Stanley, from Schorin and Weinreich (1998).

Among the sources of illiquidity that promote, or limit, the use of CDOs are adverse selection, trading costs, and moral hazard.

With regard to adverse selection, enough private information may exist about the credit quality of a junk bond or a bank loan that an investor is concerned about being "picked off" when trading such an instrument. For instance, a better-informed seller has an option to trade or not at the given price. The value of this option is related to the quality of the seller's private information. Given the risk of being picked off, the buyer offers a price that, on average, is below the price at which the asset would be sold in a setting of symmetric information. This reduction in price as a result of adverse selection is sometimes called a "lemon's premium" (Akerlof 1970).

In general, adverse selection cannot be eliminated by securitization of assets in a CDO, but it can be mitigated. The seller achieves a higher total valuation (for what is sold and what is retained) by designing the $\mathrm{CDO}$ structure so as to concentrate into small subordinate tranches the majority of the risk that may be cause for adverse selection. For example, a large senior tranche, relatively immune to the effects of adverse selection, can be sold at a small lemon's premium. The issuer can retain, on average, significant fractions of the smaller subordinate tranches, which are more subject to adverse selection. For models supporting this design and retention behavior, see DeMarzo (1999) and DeMarzo and Duffie (1999).
For a relatively small junk bond or a single bank loan to a relatively obscure borrower, the market of potential buyers and sellers may be small; thus, trading may be costly. ${ }^{2}$ Searching for such buyers can be expensive, for example, and to sell such an illiquid asset quickly, one may be forced to sell to the highest bidder among the relatively few buyers with whom one can negotiate on short notice. One's negotiating position may also be poorer than it would be in an active market. The value of the asset is correspondingly reduced. Potential buyers recognize that they are placing themselves at the risk of facing the same situation when they try to resell in the future, which results in yet lower valuations. The net cost of bearing these costs may be reduced through securitization into relatively large homogeneous senior CDO tranches, perhaps with significant retention of smaller and less easily traded junior tranches.

Moral hazard, in the context of CDOs, bears on the issuer's or CDO manager's incentives to select high-quality assets for the $\mathrm{CDO}$ and to engage in costly enforcement of covenants and other restrictions on the behavior of obligors. Securitizing and selling a significant portion of the cash flows of the underlying assets dilute these incentives. Reductions in value through lack of effort are borne to some extent by investors. Also, the opportunity may arise for "cherry picking" (sorting assets into the issuer's own portfolio or into the SPV portfolio based on the issuer's private information). In addition, opportunities may arise for front running, in which a CDO manager trades on its own account 
in advance of trades on behalf of the CDO. These moral hazards act against the creation of CDOs, because the incentives to select and monitor assets promote greater efficiency and higher valuation if the issuer retains a 100 percent interest in the asset cash flows.

The opportunity to reduce the other market imperfections through a CDO may be sufficiently large-especially in light of the advantages in building and maintaining a reputation for not exploiting CDO investors-to offset the effects of moral hazard. In this case, the issuer has an incentive to design the CDO so that the issuer retains a significant portion of one or more subordinate tranches that would be among the first to suffer losses stemming from poor monitoring or poor asset selection. Doing so demonstrates a degree of commitment to diligent efforts to manage the issue. Similarly, for arbitrage CDOs, a significant portion of the management fees may be subordinated to the issued tranches (Schorin and Weinreich 1998). In light of this commitment, investors may be willing to pay more for tranches, and the total valuation to the issuer will be higher than in an unprioritized structure, such as a straight equity pass-through security. Innes (1990) described a model that supports this motive for security design.

An example of a CLO structure consistent with this theory is shown in Figure 2. The figure illustrates one of a pair of CLO cash flow structures issued by NationsBank in 1997. A senior tranche of $\$ 2$ billion in face value, whose credit rating is AAA, is followed by successively lower subordination tranches, with their ratings. The bulk of the underlying assets are floating-rate NationsBank loans rated $\mathrm{BBB}$ or $\mathrm{BB}$. Any fixed-rate loans were hedged in terms of interest rate risk by fixed-to-floating interest rate swaps. As predicted by theory, NationsBank retained the majority of the (unrated) lowest tranche.

Our valuation model does not deal directly with the effects of market imperfections. It takes as given the default risk of the underlying loans and assumes that investors are symmetrically informed. Although this approach is not perfectly realistic, it is not necessarily inconsistent with the roles of moral hazard or adverse selection in the original security design. For example, DeMarzo and Duffie demonstrated a "fully separating equilibrium," in which the sale price of the security or the amount retained by the seller signals to all investors any of the seller's privately held valuerelevant information. Moral hazard can be addressed by the model because the diligence of the issuer or manager is, to a large extent, determined by the security design and the fractions retained by the issuer. Once these factors are known, the default risk of the underlying debt is also known. Our simple model does not, however, account for the valuation effects of many other forms of market imperfections. Moreover, inferring separate risk premiums for default timing and default recovery from the prices of the underlying debt and market risk-free interest rates is generally difficult (see Duffie and Singleton 1999.) These risk premiums

\section{Figure 2. NationsBank CLO Tranches for Three-Year Floating Rate Notes}

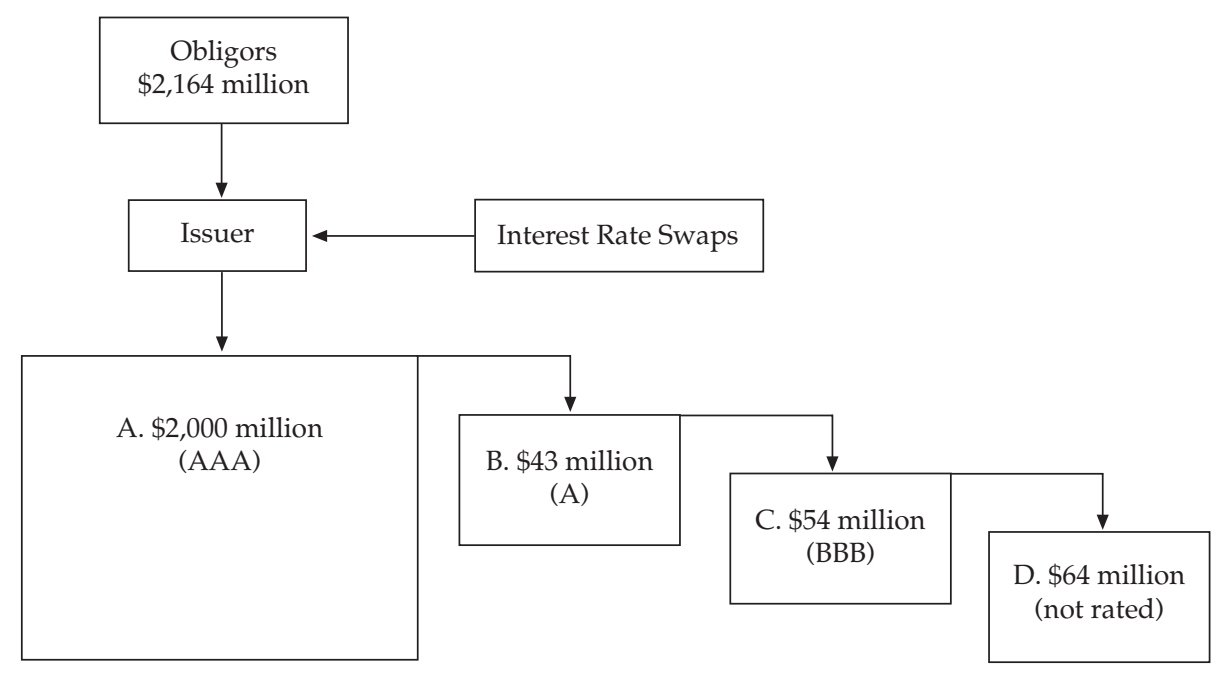

Source: Fitch 
play separate roles in the valuation of CDO tranches. We simply take these risk premiums as given in the form of "risk-neutral" parametric models for default timing and recovery distributions under an equivalent martingale measure.

\section{Default Risk Model}

We lay out some of the basic default modeling for the underlying collateral. First, we propose a simple model for the default risk of one obligor. Then, we turn to the multi-issuer setting. Throughout, we work under risk-neutral probabilities, so value is given by expectations of discounted future cash flows. If objective likelihoods or variances are of interest, however, the results should be interpreted as if the probabilities were actual, not risk neutral.

Obligor Default Intensity. We suppose that each underlying obligor defaults at some expected arrival rate. The idea is that at each time $t$ before the default time $\tau$ of the given obligor, the default arrives at some "intensity" $\lambda(t)$, given all currently available information. We thus have the approximation

$$
P_{t}(\tau<t+\Delta t) \cong \lambda(t) \Delta t
$$

for the conditional probability at the time $t$ of default within a "small" time interval $\Delta t>0 .{ }^{3}$ For example, if time is measured in years (as we do here), a current default intensity of 0.04 implies that the conditional probability of default within the next three months is approximately 0.01 . Immediately after default, the intensity drops to zero. Stochastic variation in the intensity over time, as new information becomes available, reflects any changes in perceived credit quality. Correlation across obligors in the changes over time of their credit qualities is reflected by correlation in the changes of those obligors' default intensities. Indeed, our model has the property that all correlation in default timing arises in this manner. ${ }^{4}$ We call a stochastic process $\lambda$ a pre-intensity for a stopping time $\tau$ if whenever $t<\tau$, first, the current intensity is $\lambda_{t}$ and, second,

$$
P_{t}(\tau>t+s)=E_{t}\left[\exp \left(\int_{t}^{t+s}-\lambda_{u} d u\right)\right], s>0,
$$

where $E_{t}$ denotes conditional expectation given all information at time $t$ and $s$ is the length of the period over which survival (no default) is considered. A pre-intensity need not fall to zero after default. For example, default at a constant preintensity of 0.04 means that the intensity itself is 0.04 until default and is zero thereafter.
We adopt a pre-intensity model that is a special case of the "affine" family of processes that have been used for this purpose and for modeling shortterm interest rates. ${ }^{5}$ Specifically, we suppose that each obligor's default time has some pre-intensity process $\lambda$ solving a stochastic differential equation of the form

$$
d \lambda(t)=\kappa[\theta-\lambda(t)] d t+\sigma \sqrt{\lambda(t)} d W(t)+\Delta J(t),
$$

where $W$ is a standard Brownian motion and $\Delta J(t)$ denotes any jump that occurs at time $t$ of a purejump process $J$, independent of $W$, whose jump sizes are independent and exponentially distributed with mean $\mu$ and whose jump times are those of an independent Poisson process with mean jump arrival rate $\ell$. (Jump times and jump sizes are also independent. $\left.{ }^{6}\right)$ We call a process $\lambda$ of this form (Equation 3$)$ a basic affine process with parameters $(\kappa$, $\theta, \sigma, \mu, \ell)$. These parameters can be adjusted in several ways to control the manner in which default risk changes over time. For example, we can vary the mean-reversion rate $\kappa$, the long-run mean $\bar{m}=\theta+(\ell \mu) / \kappa$, or the relative contributions to the total variance of $\lambda_{t}$ that are attributed to jump risk and to diffusive volatility.

We can also vary the relative contributions to jump risk of the mean jump size $\mu$ and the mean jump arrival rate $\ell$. A special case is the no-jump $(\ell=0)$ model of Feller (1951), which was used by Cox, Ingersoll, and Ross (1985) to model interest rates. From the results of Duffie and Kan (1996), we can calculate that for any $t$ and any $s \geq 0$,

$$
E_{t}\left[\exp \left(\int_{t}^{t+s}-\lambda_{u} d u\right)\right]=e^{\alpha(s)+\beta(s) \lambda(t)},
$$

where explicit solutions for the coefficients $\alpha(s)$ and $\beta(s)$ are provided in Appendix A. Together, Equation 2 and Equation 4 give a simple, reasonably rich, and tractable model for the default time probability distribution and how it varies at random over time as information arrives in the market.

Multi-Issuer Default Model. To study the implications of changing the correlation in the default times of the various participations (collateralizing bonds or loans) in a CDO while holding constant the default risk model of each underlying obligor, we will exploit the following result. We state that a basic affine model can be written as the sum of independent basic affine models as long as the parameters $\kappa, \sigma$, and $\mu$ governing, respectively, the mean reversion rate, diffusive volatility, and mean jump size are common to the underlying pair of independent basic affine processes.

Proposition 1: Suppose $X$ and $Y$ are independent basic affine processes with respective 
parameters $\left(\kappa, \theta_{X}, \sigma, \mu, \ell_{X}\right)$ and $\left(\kappa, \theta_{Y}, \sigma, \mu, \ell_{Y}\right)$. Then, $X+Y$ is a basic affine process with parameters $(\kappa, \theta, \sigma, \mu, \ell)$, where $\ell=\ell_{X}+\ell_{Y}$ and $\theta=\theta_{X}+\theta_{\Upsilon}{ }^{7}$

This result allows us to maintain a fixed, parsimonious, and tractable one-factor Markov model for each obligor's default probabilities while varying the correlations between different obligors' default times, as explained in the following discussion.

Suppose that the $N$ participations in the collateral pool have default times $\tau_{1}, \ldots, \tau_{N}$ with preintensity processes $\lambda_{1}, \ldots, \lambda_{N}$, respectively, that are basic affine processes. ${ }^{8}$ To introduce correlation in a simple way, we suppose that

$$
\lambda_{i}=X_{c}+X_{i}
$$

where $X_{c}$ and $X_{i}$ are basic affine processes with, respectively, parameters $\left(\kappa, \theta_{c}, \sigma, \mu, \ell_{c}\right)$ and $\left(\kappa, \theta_{i}, \sigma\right.$, $\left.\mu, \ell_{i}\right)$ and where $X_{1}, \ldots, X_{N}$ and $X_{c}$ are independent. By Proposition 1, $\lambda_{i}$ is itself a basic affine process with parameters $(\kappa, \theta, \sigma, \mu, \ell)$, where $\theta=\theta_{c}+\theta_{i}$ and $\ell=\ell_{c}+\ell_{i}$. One may view $X_{c}$ as a state process governing common aspects of economic performance in an industry, sector, or currency region and $X_{i}$ as a state variable governing the idiosyncratic default risk specific to obligor $i$. The parameter

$$
\rho=\frac{l_{c}}{l},
$$

is the long-run fraction of jumps to a given obligor's intensity that are common to all (surviving) obligors' intensities. One can also see that $\rho$ is the probability that the pre-intensity $\lambda_{j}$ jumps at time $t$ given that $\lambda_{i}$ jumps at time $t$ for any time $t$ and any distinct $i$ and $j$. We also suppose that $\theta_{c}=\rho \theta$.

Sectoral, Regional, and Global Risk. Extensions of the model to handle multifactor risk (regional, sectoral, and other sources) could easily be incorporated with repeated use of Proposition 1. Suppose, for example, that we have $S$ different sectors. We denote by $c(i)$ the sector to which the $i$ th obligor belongs; consequently, $c(1), c(2), \ldots, c(S)$ are disjoint and exhaustive subsets of $(1,2, \ldots, N)$. Suppose that the default time $\tau_{i}$ of the $i$ th obligor has a pre-intensity $\lambda_{i}=X_{i}+Y_{c(i)}+Z$, where the sector factor $Y_{c(i)}$ is common to all issuers in the "sector" $c(i)$, where $Z$ is common to all issuers, and where $\left(X_{1}, \ldots, X_{N}, Y_{1}, \ldots, Y_{S}, Z\right)$ are independent basic affine processes.

If we do not restrict the parameters of the underlying basic affine processes, then an individual obligor's pre-intensity need not itself be a basic affine process, but calculations are nevertheless easy. We can use the independence of the underlying state variables to see that

$E_{t}\left\{\exp \left[\int_{t}^{t+s}-\lambda_{i}(u) d u\right]\right\}$

$=\exp \left[\alpha(s)+\beta_{i}(s) X_{i}(t)+\beta_{c(i)}(s) Y_{c(i)}(t)+\beta_{z}(s) Z(t)\right]$,

where $\alpha(s)=\alpha_{i}(s)+\alpha_{c(i)}(s)+\alpha_{Z}(s)$ and all the $\alpha$ and $\beta$ coefficients are obtained explicitly from Appen$\operatorname{dix} \mathrm{A}$, from the respective parameters of the underlying basic affine processes $X_{i}, Y_{c(i)}$, and $Z$.

Even more generally, we can adopt multifactor affine models in which the underlying state variables are not independent. Interest rates that are jointly determined by an underlying multifactor affine jump diffusion model can also be accommodated. We refer the interested reader to the Duffie and Gârleanu 1999 working paper.

Recovery Risk. We suppose that, at default, any given piece of debt in the collateral pool may be sold for a fraction of its face value whose riskneutral conditional expectation, given all information available at any time $t$ before default, is a constant $\bar{f} \in(0,1)$ that does not depend on $t$. The recovery fractions of the underlying participations are assumed to be independently distributed and independent of default times and interest rates. (Here again, we are referring to risk-neutral behavior.) For simplicity, we assume throughout that the recovered fraction of face value is uniformly distributed on $(0,1)$.

Collateral Credit Spreads. We suppose for simplicity that changes in default intensities and changes in interest rates are (risk-neutrally) independent. ${ }^{9}$ Combined with the preceding assumptions, this implies that for an issuer whose default time $\tau$ has a basic affine pre-intensity process $\lambda$, a zero-coupon bond maturing at time $t$ has an initial market value of

$p[t, \lambda(0)]=\delta(t) e^{\alpha(t)+\beta(t) \lambda(0)}+\bar{f} \int_{0}^{t} \delta(u) \pi(u) d u$,

where $\delta(t)$ denotes the default-free zero-coupon discount to time $t$ and

$$
\begin{aligned}
\pi(u) & =-\frac{d}{d u} P(\tau>u) \\
& =-e^{\alpha(u)+\beta(u) \lambda(0)}\left[\alpha^{\prime}(u)+\beta^{\prime}(u) \lambda(0)\right]
\end{aligned}
$$

is the (risk-neutral) probability density at time $u$ of the default time.

The first term of Equation 8 is the market value of a claim that pays 1 at maturity in the event of survival. The second term is the market value of a claim to any default recovery between times 0 and $t$. The integral is computed numerically by use of 
our explicit solutions from Appendix A for $\alpha(t)$ and $\beta(t) .{ }^{10}$

Using this defaultable discount function, $p(\bullet)$, we can value any straight coupon bond or determine par coupon rates. For example, for quarterly coupon periods, the (annualized) par coupon rate, $c(s)$, for maturity in $s$ years (for an integer $s>0$ ) is determined at any time $t$ by the identity

$$
1=p\left(s, \lambda_{t}\right)+\frac{c(s)}{4} \sum_{j=1}^{4 s} p\left(\frac{j}{4}, \lambda_{t}\right),
$$

which is easily solved for $c(s)$.

We develop our numerical example with constant interest rates $r$, for which the risk-free discount $\delta$ has the simple form

$$
\delta(t)=e^{-r t} .
$$

Diversity Scores. A key measure of collateral diversity developed by Moody's Investors Service for CDO risk analysis is the diversity score. The diversity score of a given pool of participations is the number, $n$, of bonds in an idealized comparison portfolio that meets the following criteria:

- The total face value of the comparison portfolio is the same as the total face value of the collateral pool.

- The bonds of the comparison portfolio have equal face values.

- The comparison bonds are equally likely to default, and their default is independent.

- The comparison bonds are, in some sense, of the same average default probability as the participations of the collateral pool.

- The comparison portfolio has the same total loss risk, according to some measure of risk, as does the collateral pool.

At least in terms of publicly available information, it is not clear how the (equal) probability $p$ of default of the bonds of the comparison portfolio is determined. A method discussed by Schorin and Weinreich for this purpose is to assign a default probability corresponding to the weighted-average rating score of the collateral pool by using predetermined rating scores and weights that are proportional to face value. Given the average rating score, one can assign a default probability to the resulting "average" rating. For the choice of probability $p$, Schorin and Winreich discussed the use of the historical default frequency for that rating.

A diversity score of $n$ and a comparison-bond default probability of $p$ imply, under the independence assumption for the comparison portfolio, that the probability of $k$ defaults out of $n$ bonds of the comparison portfolio is

$$
q(k, n)=\frac{n !}{(n-k) ! k !} p^{k}(1-p)^{n-k},
$$

where $n$ ! (read " $n$ factorial") is the product $1 \times 2 \times$ $\ldots \times n$. From this "binomial-expansion" formula, a risk analysis of the $\mathrm{CDO}$ can be conducted by assuming that the performance of the collateral pool is sufficiently well approximated by the performance of the comparison portfolio.

Table 1 shows the diversity score that Moody's would apply to a collateral pool of equally sized bonds of different companies in the same industry. ${ }^{11}$ Table 1 also shows the implied probability of default of one participation given the default of another, as well as the implied correlations of the $0-1$, survival-default, random variables associated with any two participations for two levels of individual default probability, namely, $p=0.5$ and $p=0.05$.

\begin{tabular}{|c|c|c|c|c|c|}
\hline \multirow{2}{*}{$\begin{array}{l}\text { Number } \\
\text { of } \\
\text { Companies }\end{array}$} & \multirow{2}{*}{$\begin{array}{c}\text { Diversity } \\
\text { Score }\end{array}$} & \multicolumn{2}{|c|}{$\begin{array}{l}\text { Conditional Default } \\
\text { Probability }\end{array}$} & \multicolumn{2}{|c|}{$\begin{array}{c}\text { Default } \\
\text { Correlation }\end{array}$} \\
\hline & & $(p=0.5)$ & $(p=0.05)$ & $(p=0.5)$ & $(p=0.05)$ \\
\hline 1 & 1.00 & & & & \\
\hline 2 & 1.50 & 0.78 & 0.48 & 0.56 & 0.45 \\
\hline 3 & 2.00 & 0.71 & 0.37 & 0.42 & 0.34 \\
\hline 4 & 2.33 & 0.70 & 0.36 & 0.40 & 0.32 \\
\hline 5 & 2.67 & 0.68 & 0.33 & 0.36 & 0.30 \\
\hline 6 & 3.00 & 0.67 & 0.31 & 0.33 & 0.27 \\
\hline 7 & 3.25 & 0.66 & 0.30 & 0.32 & 0.26 \\
\hline 8 & 3.50 & 0.65 & 0.29 & 0.31 & 0.25 \\
\hline 9 & 3.75 & 0.65 & 0.27 & 0.29 & 0.24 \\
\hline 10 & 4.00 & 0.64 & 0.26 & 0.28 & 0.23 \\
\hline
\end{tabular}

Table 1. Diversity Scores, Conditional Default Probabilities, and Default Correlations

Note: Situations in which the number of companies is greater than 10 are evaluated on a case-by-case basis.

\section{Pricing Examples}

In this section, we apply a standard risk-neutral derivative valuation approach to the pricing of $\mathrm{CDO}$ tranches. In the absence of any tractable alternative, we use Monte Carlo simulation of the default times. Essentially, any intensity model could be substituted for the basic affine model that we have adopted here. An advantage of the affine model is the ability one has to quickly calibrate the model to the underlying participations, in terms of given correlations, default probabilities, yield spreads, and so on.

We study various alternative CDO cash flow structures and default risk parameters. The basic 
CDO structure consists of a special-purpose vehicle that acquires a collateral portfolio of participations (debt instruments of various obligors) and allocates interest, principal, and default recovery cash flows from the collateral pool to the CDO tranches-and perhaps to a manager.

Collateral. The collateral pool has $N$ participations. Each participation pays quarterly cash flows to the SPV at its coupon rate until maturity or default. At default, a participation is sold for its recovery value and the proceeds from the sale are also made available to the SPV.

Let $A(k)$ denote the subset of $\{1, \ldots, N\}$ containing the surviving participations at the $k$ th coupon period. The total interest income in coupon period $k$ is then

$$
W(k)=\sum_{i \in A(k)} M_{i} \frac{C_{i}}{n},
$$

where $M_{i}$ is the face value of participation $i$ and $C_{i}$ is the coupon rate on participation $i$.

If $B(k)$ denotes the set of participations defaulting between coupon periods $k-1$ and $k^{12}$ the total cash flow in period $k$ is

$$
Z(k)=W(k)+\sum_{i \in B(k)}\left(M_{i}-L_{i}\right),
$$

where $L_{i}$ is the loss of face value at the default of participation $i$.

For our example, the initial pool of collateral available to the CDO structure consists of $N=100$ participations that are straight quarterly coupon 10-year par bonds of equal face value. Without loss of generality, we take the face value of each bond to be 1 .

We initiate the common and the idiosyncratic risk factors, $X_{c}$ and $X_{i}$, at their long-run means, $\theta_{c}+\ell_{c} \mu / \kappa$ and $\theta_{i}+\ell_{i} \mu / \kappa$, respectively. Thus, the initial condition (and long-run mean) for each obligor's (risk-neutral) default pre-intensity is 5.33 percent. Our base-case default-risk model is defined by Parameter Set Number 1 in Table 2 and by letting $\rho=0.5$ determine the degree of diversification. The three other parameter sets shown in Table 2 are designed to illustrate the effects of replacing some or all of the diffusive volatility with jump volatility or the effects of reducing the mean jump size and increasing the mean jump arrival frequency $\ell$.

All the parameter sets have the same long-run mean $\theta+\mu l / \kappa$. The parameters $\theta, \sigma, l$, and $\mu$ were adjusted so as to maintain essentially the same term structure of zero-coupon yields, as illustrated in Figure $3 .{ }^{13}$ Table 2 provides, for each parameter set, the 10-year par-coupon spread (in basis points) and the long-run variance of $\lambda_{i}(t)$. To illustrate the qualitative differences between parameter sets, Figure 4 shows sample paths of new 10-year par spreads for two issuers, one with the base-case parameters (Set 1) and the other with pure-jump intensity (Set 2) calibrated to the same initial spread curve.

Table 2. Risk-Neutral Default Parameter Sets

\begin{tabular}{cccccccc}
\hline Set & $\kappa$ & $\theta$ & $\sigma$ & $\ell$ & $\mu$ & $\begin{array}{c}\text { Spread } \\
(\mathrm{bps})\end{array}$ & $\operatorname{var}_{\infty}$ \\
\hline 1 & 0.6 & 0.0200 & 0.141 & 0.2000 & 0.1000 & 254 & 0.42 \\
2 & 0.6 & 0.0156 & 0.000 & 0.2000 & 0.1132 & 254 & 0.43 \\
3 & 0.6 & 0.0373 & 0.141 & 0.0384 & 0.2500 & 253 & 0.49 \\
4 & 0.6 & 0.0005 & 0.141 & 0.5280 & 0.0600 & 254 & 0.41 \\
\hline
\end{tabular}

With $d_{i}$ denoting the event of default by the $i$ th participation, Table 3 shows for each parameter set and each of three levels of the correlation parameter $\rho$, the unconditional probability of default and the conditional probability of default by one participation given default by another. Table 3 also shows the diversity score of the collateral pool that is implied by matching the (risk-neutral) variance of the total loss of principal of the collateral portfolio to that of a comparison portfolio of bonds of the same individual default probabilities. ${ }^{14}$

For our basic examples, we suppose, first, that any cash in the SPV reserve account is invested at the default-free short-term rate. We later consider investment of SPV free cash flows in additional risky participations.

Sinking-Fund Tranches. We consider a CDO structure that pays SPV cash flows to a prioritized sequence of sinking-fund bonds and a junior subordinated residual.

In general, a sinking-fund bond with $n$ coupon periods per year has some remaining principal, $F(k)$, at coupon period $k$, some annualized coupon rate $c$, and a scheduled interest payment at coupon period $k$ of $F(k) c / n$. In the event that the actual interest paid, $Y(k)$, is less than the scheduled interest payment, any difference $F(k) c / n-Y(k)$ is accrued at the bond's own coupon rate, $c$, so as to generate an accrued unpaid interest at period $k$ of $U(k)$, where $U(0)=0$ and

$$
U(k)=\left(1+\frac{c}{n}\right) U(k-1)+\frac{c}{n} F(k)-Y(k) .
$$

To prioritize payments in light of the default and recovery history of the collateral pool, some prepayment of principal, $D(k)$, and some contractual 
Figure 3. Zero-Coupon Yield Spreads with and without Diffusion

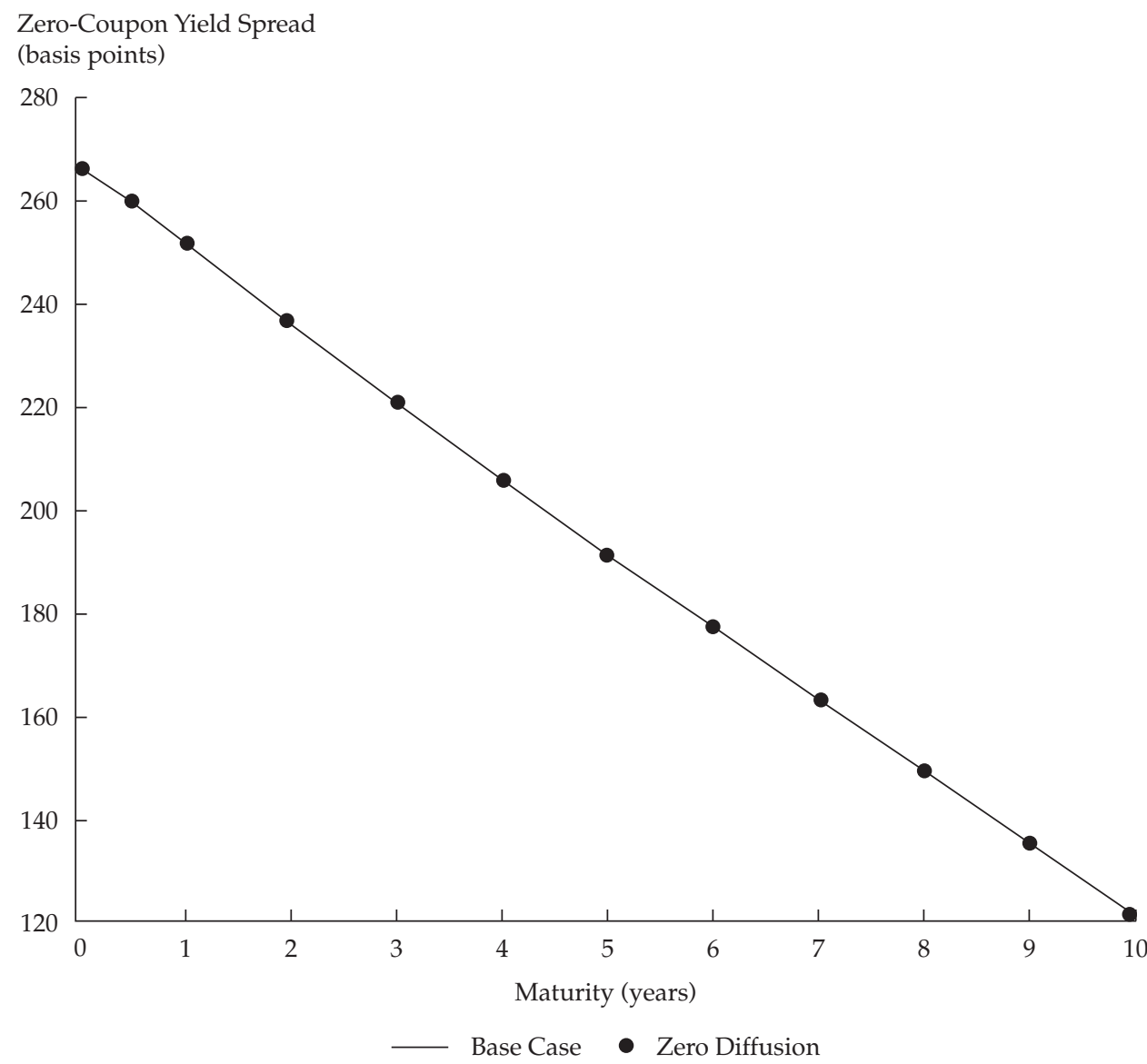

unpaid reduction in principal, $J(k)$, may also occur in period $k$. By contract, we have $D(k)+J(k) \leq F(k-$ $1)$, so the remaining principal at quarter $k$ is

$$
F(k)=F(k-1)-D(k)-J(k) \text {. }
$$

At maturity (coupon period number $K$ ), any unpaid accrued interest and unpaid principal, $U(K)$ and $F(K)$, respectively, are paid to the extent provided in the $\mathrm{CDO}$ contract. (A shortfall does not constitute default so long as the contractual prioritization scheme is maintained. ${ }^{15}$ ) The total actual payment in any coupon period $k$ is $Y(k)+D(k)$.

The par coupon rate on a given sinking-fund bond is the scheduled coupon rate $c$ with the property that the initial market value of the bond is equal to its initial face value, $F(0)$. If the default-free short rate $r(k)$ is constant, as in our results, any sinking-fund bond that pays all remaining principal and all accrued unpaid interest by or at its maturity date has a par coupon rate equal to the default-free coupon rate, no matter the timing of the interest and principal payments.

We illustrate our initial valuation results in terms of the par coupon spreads of the respective tranches, which are the excess of the par coupon rates of the tranches over the default-free par coupon rate.

Prioritization Schemes. We experiment with the relative sizes and prioritization of two CDO bond tranches, one 10-year senior sinking-fund bond with some initial principal $F_{1}(0)=P_{1}$ and one 10-year mezzanine sinking-fund bond with initial principal $F_{2}(0)=P_{2}$. The residual junior tranche receives any cash flow remaining at the end of the 10 -year structure. Because the base-case coupon rates on the senior and mezzanine $\mathrm{CDO}$ tranches are, by design, par rates, the base-case initial market value of the residual tranche is $P_{3}=100-P_{1}-P_{2}$.

At the $k$ th coupon period, tranche $j$ has a face value of $F_{j}(k)$ and accrued unpaid interest $U_{j}(k)$ calculated at its own coupon rate, $c_{j}$. Any excess cash flows from the collateral pool (interest income and default recoveries) are deposited in a reserve account. To begin, we suppose that the reserve account earns interest at the default-free oneperiod interest rate, denoted $r(k)$ at the $k$ th coupon date. At maturity, coupon period $K$, any remaining funds in the reserve account after payments at quarter $K$ to the two tranches are paid to the 
Figure 4. New 10-Year Par-Coupon Spreads for the Base-Case Parameters and for the Pure-Jump Intensity Parameters

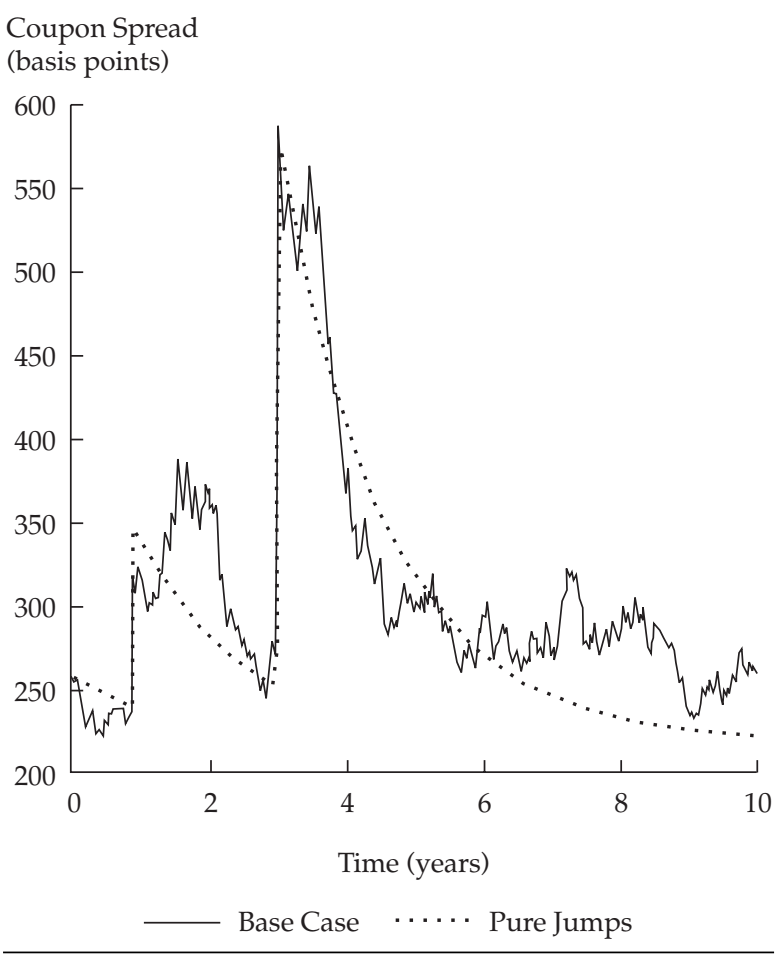

subordinated residual tranche. (Later, we investigate the effects of investing the reserve account in additional participations that are added to the collateral pool.) We ignore management fees.

This example investigates valuation for two prioritization schemes: Given the definition of the sinking funds in the previous subsection, complete specification of cash flows to all tranches requires only that we define for the senior sinking fund and for the mezzanine sinking fund, respectively, the actual interest payments, $Y_{1}(k)$ and $Y_{2}(k)$; any payments of principal, $D_{1}(k)$ and $D_{2}(k)$; and any contractual reductions in principal, $J_{1}(k)$ and $J_{2}(k)$.

Under our uniform prioritization scheme, interest $W(k)$ collected from the surviving participations is allocated in priority order, with the senior tranche getting $Y_{1}(k)=\min \left[U_{1}(k), W(k)\right]$ and the mezzanine getting $Y_{2}(k)=\min \left[U_{2}(k), W(k)-Y_{1}(k)\right]$.
The reserve available before payments at period $k, R(k)$, is thus defined by [recall that $Z(k)$ is the total cash flow from the participations in period $k]$

$$
\begin{aligned}
R(k)= & {\left[1+\frac{r(k)}{4}\right] } \\
& \times\left[R(k-1)-Y_{1}(k-1)-Y_{2}(k-1)\right] \\
& +Z(k) .
\end{aligned}
$$

Unpaid reductions in principal from default losses occur in reverse priority order, so the junior residual tranche suffers the reduction

$$
J_{3}(k)=\min \left[F_{3}(k-1), H(k)\right],
$$

where

$H(k)=\max \left\{\sum_{i \in B(k)} L_{i}-\left[W(k)-Y_{1}(k)-Y_{2}(k)\right], 0\right\}$,

is the total of default losses since the previous coupon date less collected and undistributed interest income. Then, the mezzanine and senior tranches are successively reduced in principal by, respectively,

$$
J_{2}(k)=\min \left[F_{2}(k-1), H(k)-J_{3}(k)\right]
$$

and

$$
J_{1}(k)=\min \left[F_{1}(k-1), H(k)-J_{3}(k)-J_{2}(k)\right] .
$$

Under uniform prioritization, no early payments of principal are made, so $D_{1}(k)=D_{2}(k)=0$ for $k<K$. At maturity, the remaining reserve is paid in priority order, and principal and accrued interest are treated identically, so without loss of generality for purposes of valuation, we take

$$
\begin{aligned}
& Y_{1}(K)=Y_{2}(K)=0, \\
& D_{1}(K)=\min \left[F_{1}(K)+U_{1}(K), R(K)\right],
\end{aligned}
$$

and

$$
D_{2}(K)=\min \left[F_{2}(K)+U_{2}(K), R(K)-D_{1}(K)\right] .
$$

\begin{tabular}{|c|c|c|c|c|c|c|c|}
\hline \multirow[b]{2}{*}{ Set } & \multirow[b]{2}{*}{$P\left(d_{i}\right)$} & \multicolumn{2}{|c|}{$\rho=0.1$} & \multicolumn{2}{|c|}{$\rho=0.5$} & \multicolumn{2}{|c|}{$\rho=0.9$} \\
\hline & & $P\left(d_{i} \mid d_{j}\right)$ & $\begin{array}{c}\text { Diversity } \\
\text { Score }\end{array}$ & $P\left(d_{i} \mid d_{j}\right)$ & $\begin{array}{l}\text { Diversity } \\
\text { Score }\end{array}$ & $P\left(d_{i} \mid d_{j}\right)$ & $\begin{array}{c}\text { Diversity } \\
\text { Score }\end{array}$ \\
\hline 1 & 0.386 & 0.393 & 58.5 & 0.420 & 21.8 & 0.449 & 13.2 \\
\hline 2 & 0.386 & 0.393 & 59.1 & 0.420 & 22.2 & 0.447 & 13.5 \\
\hline 3 & 0.386 & 0.392 & 63.3 & 0.414 & 25.2 & 0.437 & 15.8 \\
\hline 4 & 0.386 & 0.393 & 56.7 & 0.423 & 20.5 & 0.454 & 12.4 \\
\hline
\end{tabular}

The residual tranche finally collects

$$
D_{3}(K)=R(K)-Y_{1}(K)-D_{1}(K)-Y_{2}(K)-D_{2}(K) .
$$

For the alternative fast-prioritization scheme, the senior tranche is allocated interest and principal

Table 3. Conditional Probabilities of Default and Diversity Scores 
payments as quickly as possible until maturity or until its principal remaining is reduced to zero, whichever is first. Until the senior tranche is paid in full, the mezzanine tranche accrues unpaid interest at its coupon rate. Then, the mezzanine tranche is paid interest and principal as quickly as possible until maturity or until the mezzanine tranche is retired. Finally, any remaining cash flows are allocated to the residual tranche. Specifically, in coupon period $k$, the senior tranche is allocated the interest payment,

$$
Y_{1}(k)=\min \left[U_{1}(k), Z(k)\right]
$$

and the principal payment

$$
D_{1}(k)=\min \left[F_{1}(\mathrm{k}-1), Z(k)-Y_{1}(k)\right],
$$

where the total cash generated by the collateral pool, $Z(k)$, is again defined by Equation 14. The mezzanine receives the interest payments,

$Y_{2}(k)=\min \left[U_{2}(k), Z(k)-Y_{1}(k)-D_{1}(k)-Y_{2}(k)\right]$

and principal payments

$D_{2}(k)=\min \left[F_{2}(k-1), Z(k)-Y_{1}(k)-D_{1}(k)-Y_{2}(k)\right]$.

Finally, any residual cash flows are paid to the junior subordinated tranche. For this scheme, no contractual reductions in principal occur [that is, $\left.J_{i}(k)=0\right]$.

In practice, many other types of prioritization schemes are possible. For example, during the life of a CDO, failure to meet certain contractual overcollateralization ratios in many cases triggers a shift to some version of fast prioritization. For our examples, the CDO yield spreads for uniform and fast prioritization would provide upper and lower bounds, respectively, on the senior spreads that would apply if one were to add such a feature to the uniform prioritization scheme that we illustrated.

Simulation Methodology. Our computational approach consists of simulating piecewise linear approximations of the paths of $X_{c}$ and $X_{1}, \ldots, X_{N}$ for time intervals of some relatively small fixedlength $\Delta t$. (We use a $\Delta t$ interval of one week.) Defaults during one of these intervals are simulated at the corresponding discretization of the total arrival intensity,

$$
\Lambda(t)=\sum_{i} \lambda_{i}(t) 1_{A(i, t)},
$$

where the variable $1_{A(i, t)}$ equals 1 if issuer $i$ has not defaulted by $t$ and equals 0 otherwise. (That is, only the intensities of the participations still alive are summed.) When a default arrives, the identity of the defaulter is drawn at random, with the probability that $i$ is selected as the defaulter given by the discretization approximation of $\lambda_{i}(t) 1_{A(i, t)} / \Lambda(t)$. The prob- ability that more than one default will occur during one time step is very small; hence, we ignore it.

Based on experimentation, we chose to simulate 10,000 pseudo-independent scenarios. ${ }^{16}$

Results for Par CDO Spreads. The estimated par spreads of the senior $\left(s_{1}\right)$ and mezzanine $\left(s_{2}\right)$ CDO tranches for the four-parameter sets are shown in Table 4 for various levels of overcollateralization and for the two prioritization schemes. To illustrate the accuracy of the simulation methodology, we show in parentheses estimates of the standard deviation of these estimated spreads resulting from "Monte Carlo noise." Table 5 and Table 6 show estimated par spreads for the case of, respectively, "low" ( $\rho=0.1)$ and "high" $(\rho=0.9)$ default correlations. In all these examples, the risk-free rate is 0.06 and no management fees are considered.

Table 4. Par Spreads $(\rho=0.5)$

\begin{tabular}{|c|c|c|c|c|}
\hline \multirow[b]{2}{*}{ Set } & \multicolumn{2}{|c|}{ Uniform Scheme } & \multicolumn{2}{|c|}{ Fast Scheme } \\
\hline & $s_{1}$ & $s_{2}$ & $s_{1}$ & $s_{2}$ \\
\hline
\end{tabular}
(estimated standard deviation in parentheses)

Principal: $P_{1}=92.5 ; P_{2}=5$

\begin{tabular}{llllc}
1 & 18.7 bps & 636 bps & 13.5 bps & 292 bps \\
& $(1)$ & $(16)$ & $(0.4)$ & $(1.6)$ \\
2 & 17.9 & 589 & 13.5 & 270 \\
& $(1)$ & $(15)$ & $(0.5)$ & $(1.6)$ \\
3 & 15.3 & 574 & 11.2 & 220 \\
& $(1)$ & $(14)$ & $(0.5)$ & $(1.5)$ \\
4 & 19.1 & 681 & 12.7 & 329 \\
& $(1)$ & $(17)$ & $(0.4)$ & $(1.6)$ \\
& & & & \\
Principal: $P_{1}=80 ; P_{2}=10$ & & & \\
1 & 1.64 bps & 67.4 bps & $0.92 \mathrm{bps}$ & $38.9 \mathrm{bps}$ \\
& $(0.1)$ & $(2.2)$ & $(0.1)$ & $(0.6)$ \\
2 & 1.69 & 66.3 & 0.94 & 39.5 \\
& $(0.1)$ & $(2.2)$ & $(0.01)$ & $(0.6)$ \\
3 & 2.08 & 51.6 & 1.70 & 32.4 \\
& $(0.2)$ & $(2.0)$ & $(0.2)$ & $(0.6)$ \\
4 & 1.15 & 68.1 & 0.37 & 34.6 \\
& $(0.1)$ & $(2.0)$ & $(0.2)$ & $(0.6)$ \\
\hline
\end{tabular}

Figure 5 and Figure 6 illustrate the impacts on the market values of the three tranches of a given $\mathrm{CDO}$ structure of changing the correlation parameter $\rho$ (with uniform prioritization). The base-case CDO structures used for this illustration were determined by uniform prioritization of senior and mezzanine tranches whose coupon rates are at par for the base-case Parameter Set 1 and with the correlation parameter $\rho=0.5$. For example, suppose this correlation parameter is moved from the base 
Table 5. Par Spreads $(\rho=0.1)$

\begin{tabular}{|c|c|c|c|c|}
\hline \multirow[b]{2}{*}{ Set } & \multicolumn{2}{|c|}{ Uniform Scheme } & \multicolumn{2}{|c|}{ Fast Scheme } \\
\hline & $s_{1}$ & $s_{2}$ & $s_{1}$ & $s_{2}$ \\
\hline \multicolumn{5}{|c|}{ Principal: $P_{1}=92.5 ; P_{2}=5$} \\
\hline 1 & 6.7 bps & 487 bps & $2.7 \mathrm{bps}$ & $122 \mathrm{bps}$ \\
\hline 2 & 6.7 & 492 & 2.9 & 117 \\
\hline 3 & 6.3 & 473 & 2.5 & 102 \\
\hline 4 & 7.0 & 507 & 2.7 & 137 \\
\hline \multicolumn{5}{|c|}{ Principal: $P_{1}=80 ; P_{2}=10$} \\
\hline 1 & $0.27 \mathrm{bps}$ & $17.6 \mathrm{bps}$ & $0.13 \mathrm{bps}$ & $7.28 \mathrm{bps}$ \\
\hline 2 & 0.31 & 17.5 & 0.15 & 7.92 \\
\hline 3 & 0.45 & 14.9 & 0.40 & 6.89 \\
\hline 4 & 0.16 & 19.0 & 0.05 & 6.69 \\
\hline
\end{tabular}

Table 6. Par Spreads $(\rho=0.9)$

\begin{tabular}{|c|c|c|c|c|}
\hline \multirow[b]{2}{*}{ Set } & \multicolumn{2}{|c|}{ Uniform Scheme } & \multicolumn{2}{|c|}{ Fast Scheme } \\
\hline & $s_{1}$ & $s_{2}$ & $s_{1}$ & $s_{2}$ \\
\hline \multicolumn{5}{|c|}{ Principal: $P_{1}=92.5 ; P_{2}=5$} \\
\hline 1 & 30.7 bps & $778 \mathrm{bps}$ & 23.9 bps & 420 bps \\
\hline 2 & 29.5 & 687 & 23.7 & 397 \\
\hline 3 & 25.3 & 684 & 20.6 & 325 \\
\hline 4 & 32.1 & 896 & 23.1 & 479 \\
\hline \multicolumn{5}{|c|}{ Principal: $P_{1}=80 ; P_{2}=10$} \\
\hline 1 & $3.17 \mathrm{bps}$ & $113 \mathrm{bps}$ & $1.87 \mathrm{bps}$ & $68.8 \mathrm{bps}$ \\
\hline 2 & 3.28 & 112 & 1.95 & 70.0 \\
\hline 3 & 4.03 & 90 & 3.27 & 60.4 \\
\hline 4 & 2.52 & 117 & 1.06 & 65.4 \\
\hline
\end{tabular}

case of 0.5 to 0.9 . Figure 6 , which treats the case of relatively little subordination available to the senior tranche $\left(P_{1}=92.5\right)$, shows that the loss in diversification reduces the market value of the senior tranche from 92.5 to about 91.9. The market value of the residual tranche, which benefits from volatility in the manner of a call option, increases from 2.5 to approximately 3.2, a dramatic relative change. Although a precise statement of convexity is complicated by the timing of the prioritization effects, the effect illustrated by Figures 5 and 6 is along the lines of Jensen's inequality; an increase in correlation also increases the (risk-neutral) variance of the total loss of principal. These opposing reactions to diversification of the senior and junior tranches also show that the residual tranche may offer some benefits to certain investors as a volatility hedge against default risk for the senior tranche.

The mezzanine tranche absorbs the net effect of the impacts of correlation changes on the market values of the senior and junior residual tranches (in this example, the result is a decline in market value of the mezzanine from 5.0 to approximately 4.9), which it must do because the total market value of

\section{Figure 5. Impact on Tranche Value of Correla- tion: High Overcollateralization $\left(P_{1}=80\right)$}

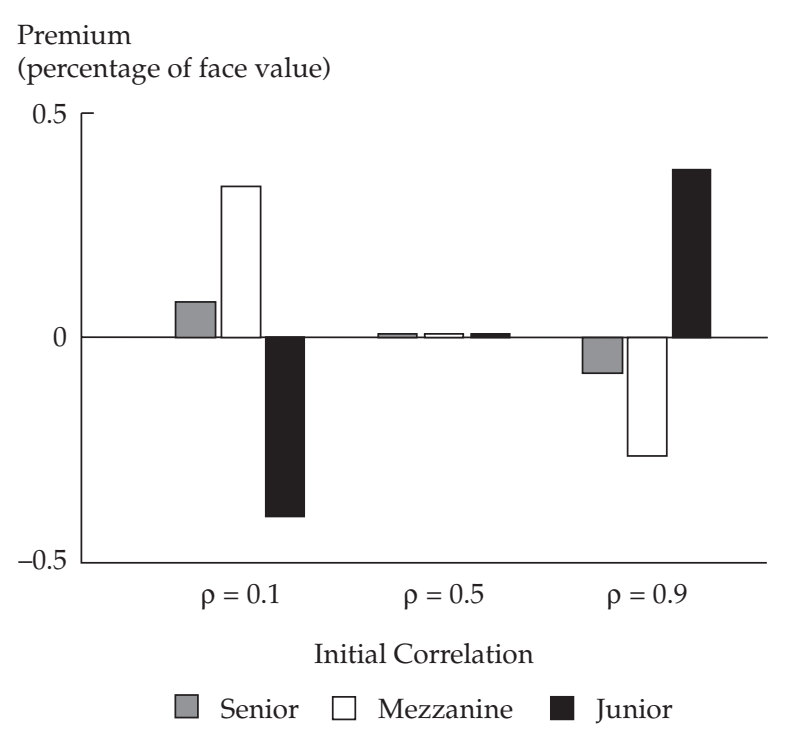

Note: Uniform prioritization. The premium is the market value net of par.

\section{Figure 6. Impact on Tranche Value of Correla- tion: Low Overcollateralization $\left(P_{1}=92.5\right)$}

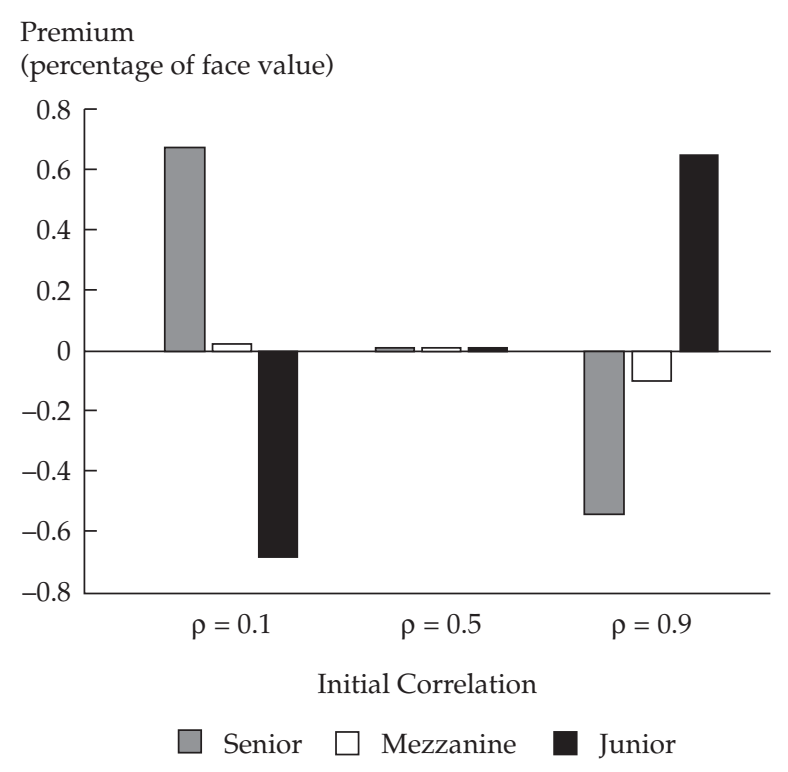

Note: Uniform prioritization. The premium is the market value net of par.

the collateral portfolio is not affected by the correlation of default risk. These effects can be compared with the impact of correlation on the par spreads of the senior and mezzanine tranches that are shown in Tables 4, 5, and 6. Clearly, given the relatively 
small size of the mezzanine principal, the mezzanine par spreads can be dramatically influenced by correlation. Moreover, experimenting with various mezzanine overcollateralization values shows that the effect is ambiguous: Increasing default correlation may raise or lower mezzanine spreads.

Prioritization Scheme. For our example, ensuring faster payments to the senior and then to the mezzanine tranches makes these tranches safer; that is, their par coupon spreads are smaller when the fast prioritization scheme is adopted. For the senior tranche, this statement holds for two reasons: This tranche risks no contractual loss of principal (and hence no contractual loss of future interest) and it loses no interest payments to the mezzanine tranche. For the mezzanine tranche, the statement holds in our example because the effect of experiencing no contractual principal losses is stronger than that of postponing the interest payments, which carries the risk of not receiving them in full. Tables 4-6 provide the computed spreads.

Risky Reinvestment. This method can also be used to allow for collateral assets that mature before the termination of the CDO. The default intensity of each new collateral asset is of the type given by Equation 5, where $X_{i}$ is initialized at the time of the purchase at the initial base-case level (long-run mean of $\lambda_{i}$ ). Figure 7 and Figure 8 show the effect of changing from safe to risky reinvestment (with uniform prioritization). Given the "short-option" aspect of the senior tranche, it becomes less valuable when reinvestment becomes risky. Note that the mezzanine tranche benefits from the increased variance in this case.

\section{Analytical Results}

In this section, exploiting the symmetry assumptions of our special example, we provide analytical results for the probability distribution for the number of defaulting participations and the total of default losses of principal, including the effects of random recovery.

The key to calculating these probability distributions exactly is the ability to explicitly compute the probability of survival of all participations in any chosen subgroup of obligors. These explicit probabilities must be evaluated with extremely high numerical accuracy, however, because of the numerous combinations of subgroups to be considered.

For a given time horizon $T$, let $d_{j}$ denote the event that obligor $j$ defaults by $T$. That is, $d_{j}=$ $\left\{\tau_{j}<T\right\}$. Also, let $d_{j}^{c}$ denote the event complementary to $d_{j}$, namely, $d_{j}^{c}=\left\{\tau_{j}>T\right\}$. Let $M$ denote the number of defaults. Assuming symmetry (invari-
Figure 7. Risky Reinvestment: Senior Tranche Spreads

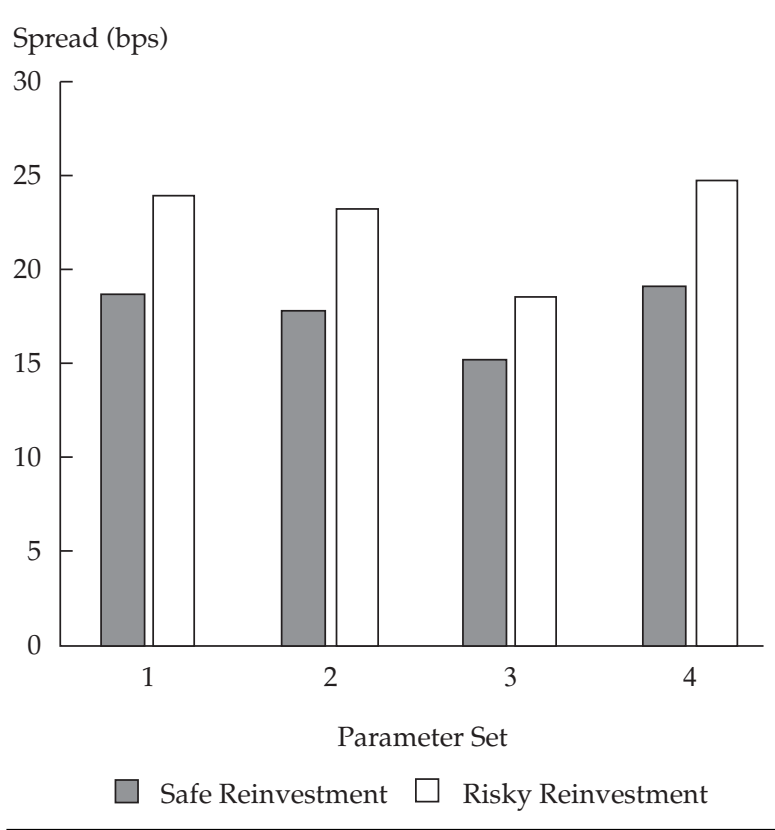

Figure 8. Risky Reinvestment: Mezzanine Tranche Spreads

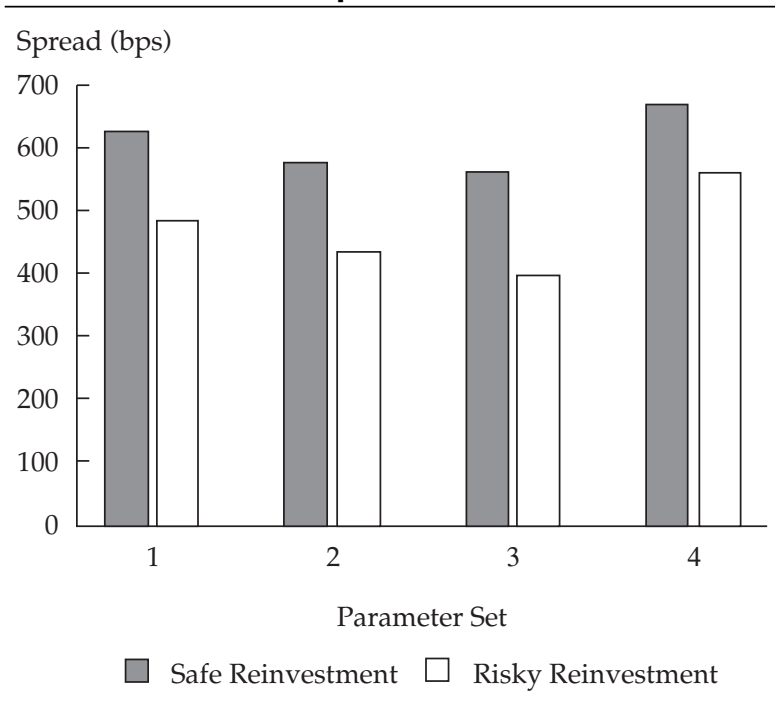

ance under permutation) in the unconditional joint distribution of default times,

$$
\begin{aligned}
& P(M=k)= \\
& \left(\begin{array}{l}
N \\
k
\end{array}\right) P\left(d_{1} \cap \ldots \cap d_{k} \cap d_{k+1}^{c} \cap \ldots \cap d_{N}^{c}\right),
\end{aligned}
$$

where

$$
\left(\begin{array}{l}
N \\
k
\end{array}\right)=\frac{N !}{(N-k) ! k !} .
$$

We let $q(k, N)=P\left(d_{1} \cap \ldots \cap d_{k} \cap d_{k+1}^{c} \cap \ldots \cap d_{N}^{c}\right)$. The probability $p_{j}=P\left(d_{1} \cup \ldots \cup d_{j}\right)$ that at least one 
of the first $j$ names will default by $T$ is computed later; for now, we take this calculation as given.

Proposition 2: We have ${ }^{17}$

$$
q(k, N)=\sum_{j=1}^{N}(-1)^{(j+k+N+1)}\left(\begin{array}{c}
k \\
N-j
\end{array}\right) p_{j} .
$$

A proof, found in the Duffie and Gârleanu 1999 working paper, is based on a careful counting of the number of scenarios in which $k$ participations default. Using the fact that the pre-intensity of the first-to-arrive $\tau^{(j)}=\min \left(\tau_{1}, \ldots, \tau_{j}\right)$ of the stopping times $\tau_{1}, \ldots, \tau_{j}$ is $\lambda_{1}+\ldots+\lambda_{j}$ and using the independence of $X_{1}, \ldots, X_{N}$ and $X_{c}$, we have

$$
\begin{aligned}
p_{j} & =1-P\left[\tau^{(j)}>T\right] \\
& =1-E\left\{\exp \left[-\int_{0}^{T} \sum_{i=1}^{j} \lambda_{i}(t) d t\right]\right\} \\
& =1-e^{\alpha_{c}(T)+\beta_{c}(T) X_{c}(0)+j \alpha_{i}(T)+j \beta_{i}(T) X_{i}(0)},
\end{aligned}
$$

where $\alpha_{c}(T)$ and $\beta_{c}(T)$ are given explicitly in Appen$\operatorname{dix} \mathrm{A}$ as the solutions of the ordinary differential
Equations A2 and A3 for the case in which $n=-\kappa$, $p=\sigma^{2}, q=-j, \ell=\ell_{c}$, and $m=\kappa \theta_{c} ; \alpha_{i}(T)$ and $\beta_{i}(T)$ are the explicitly given solutions of Equations $\mathrm{A} 2$ and A3 for the case in which $n=-\kappa, p=\sigma^{2}, q=-1, \ell=\ell_{i}$ and $m=\kappa \theta_{i}$.

It is not hard to see how to generalize Proposition 2 so as to accommodate more than one type of intensity-that is, how to treat a case with several internally symmetric pools. Introducing each such group increases by one the dimensions of the array $p$, however, and the summation. Thus, given the relatively lengthy computation required to obtain adequate accuracy for even two subgroups of issuers, one might prefer simulation to this analytical approach for multiple types of issuers.

Based on this analytical method, Figure 9 shows the probability $q(k, 100)$ of $k$ defaults within 10 years out of the original group of 100 issuers for Parameter Set 1 for a correlation-determining parameter $\rho$ that is high (0.9) or low (0.1). Figure 10 shows the associated cumulative probability functions, including the base case of $\rho=0.5$. For example, from Figure 9, the likelihood of at least 60 defaults out of the original 100 participations in 10

Figure 9. Probability of $k$ Defaults for High and Low Correlation

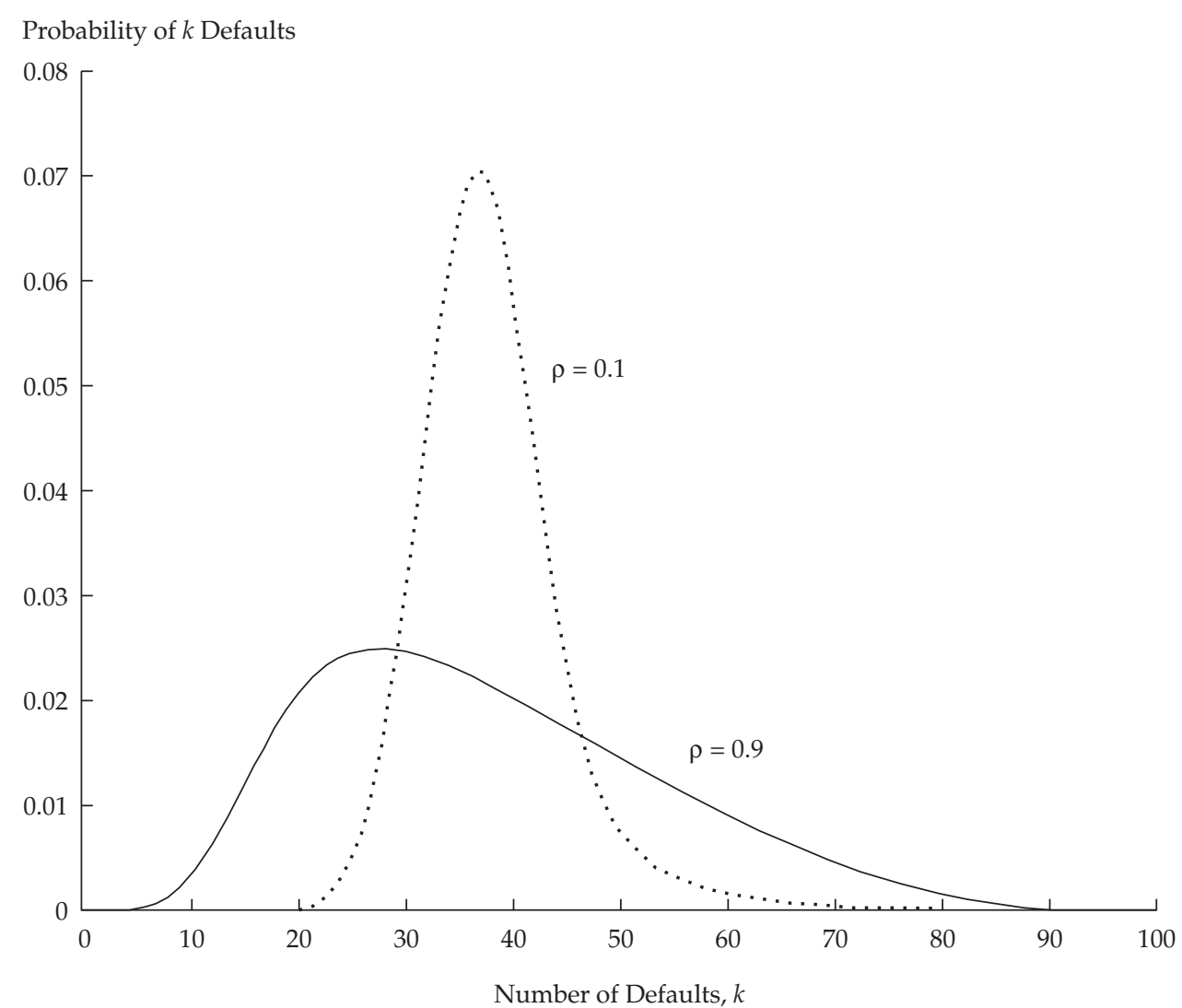


Figure 10. Cumulative Probability of Number of Defaults: High, Low, and Base-Case Correlation

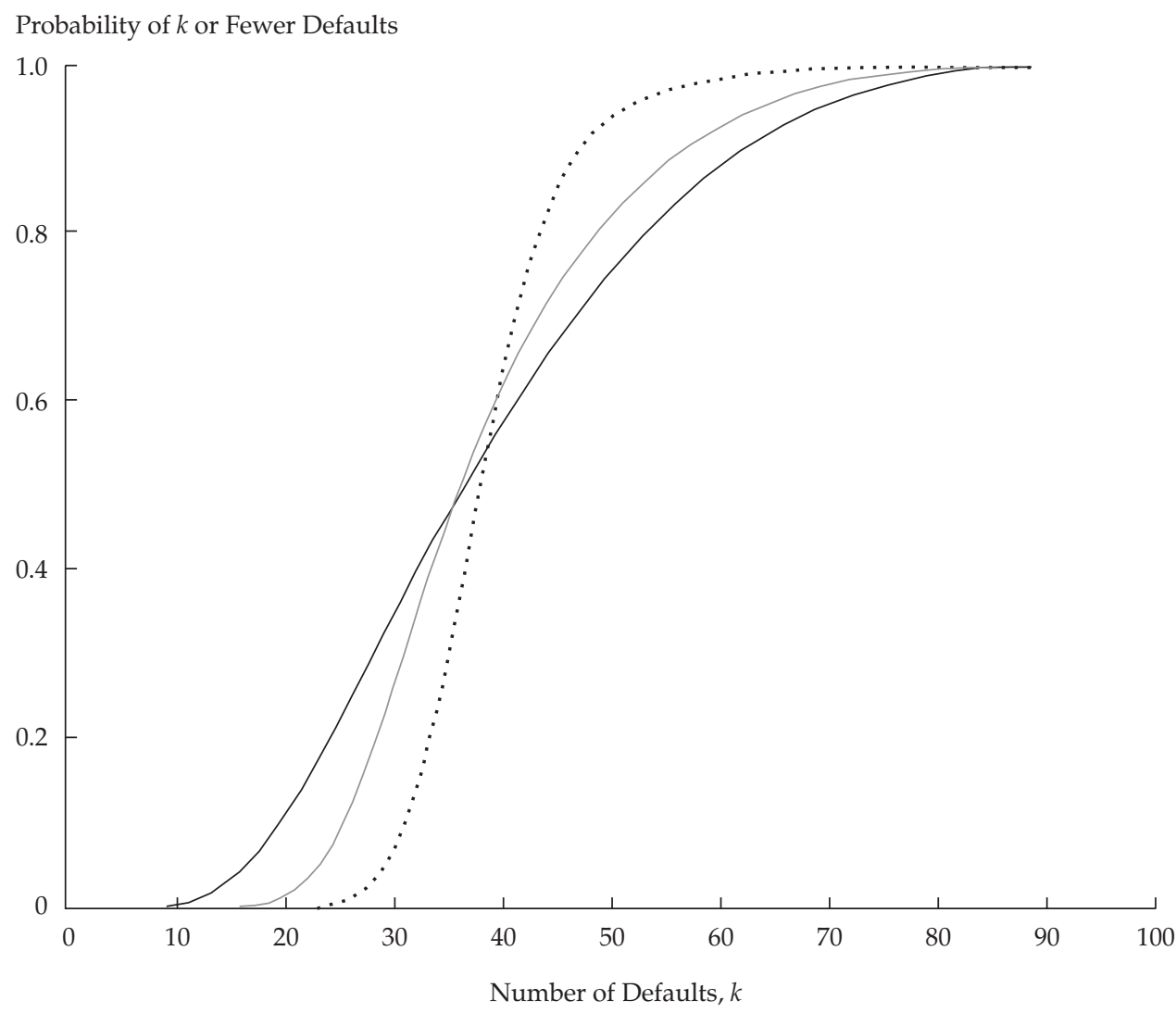

Number of Defaults, $k$

years is on the order of 1 percent for the lowcorrelation case, whereas it is roughly 12 percent for the high-correlation case. One can use this method to compare the probability $q(k, 100)$ of $k$ defaults across all four parameter sets. ${ }^{18}$

One can also compute analytically the likelihood of a total loss of principal of a given amount $x .{ }^{19}$ The approach is to add up, over $k$, the probabilities $q(k, 100)$ of $k$ defaults multiplied by the probabilities that the total loss of principal from $k$ defaults is at least $x \cdot{ }^{20} \mathrm{~A}$ sample of the resulting loss distributions is illustrated in Figure 11.

One can also analytically compute the variance of total loss of principal, from which come diversity scores, as tabulated for our example in Table 3. A description of the computation of diversity scores for a general pool of collateral, not necessarily with symmetric default risk, is in Appendix B. Given a (risk-neutral) diversity score of $n$, one can estimate CDO yield spreads by a much simpler algorithm, which approximates by substituting the comparison portfolio of $n$ independently defaulting participations for the actual collateral portfolio.

The default times can be independently simulated directly from an explicit unconditional distri- bution rather than through a much more arduous simulation of the pre-intensity processes. The algorithm is roughly as follows:

- Simulate $n$ draws from the explicit distribution of the default time of a participation in the comparison portfolio. Record those default times that are before $T$ - say, $M$ in numberand ignore the others.

- Simulate $M$ fractional losses of principal.

- Allocate cash flows to the CDO tranches, period by period, according to the desired prioritization scheme.

- Discount the cash flows of each CDO tranche to a present value at risk-free rates.

- For each tranche, average the discounted cash flows over independently generated scenarios. A comparison of the resulting approximation of CDO spreads with those computed earlier is provided for certain cases in Figures 12-14. For well-collateralized tranches, the diversity-based estimates of spreads are reasonably accurate (as shown in Figures 12 and 14), at least relative to the uncertainty that one would in any case have regarding the actual degree of diversification in the collateral pool. For highly subordinated tranches and with moderate or large default correlations, the 
Figure 11. Probability Density of Total Losses of Principal through Default: High Correlation

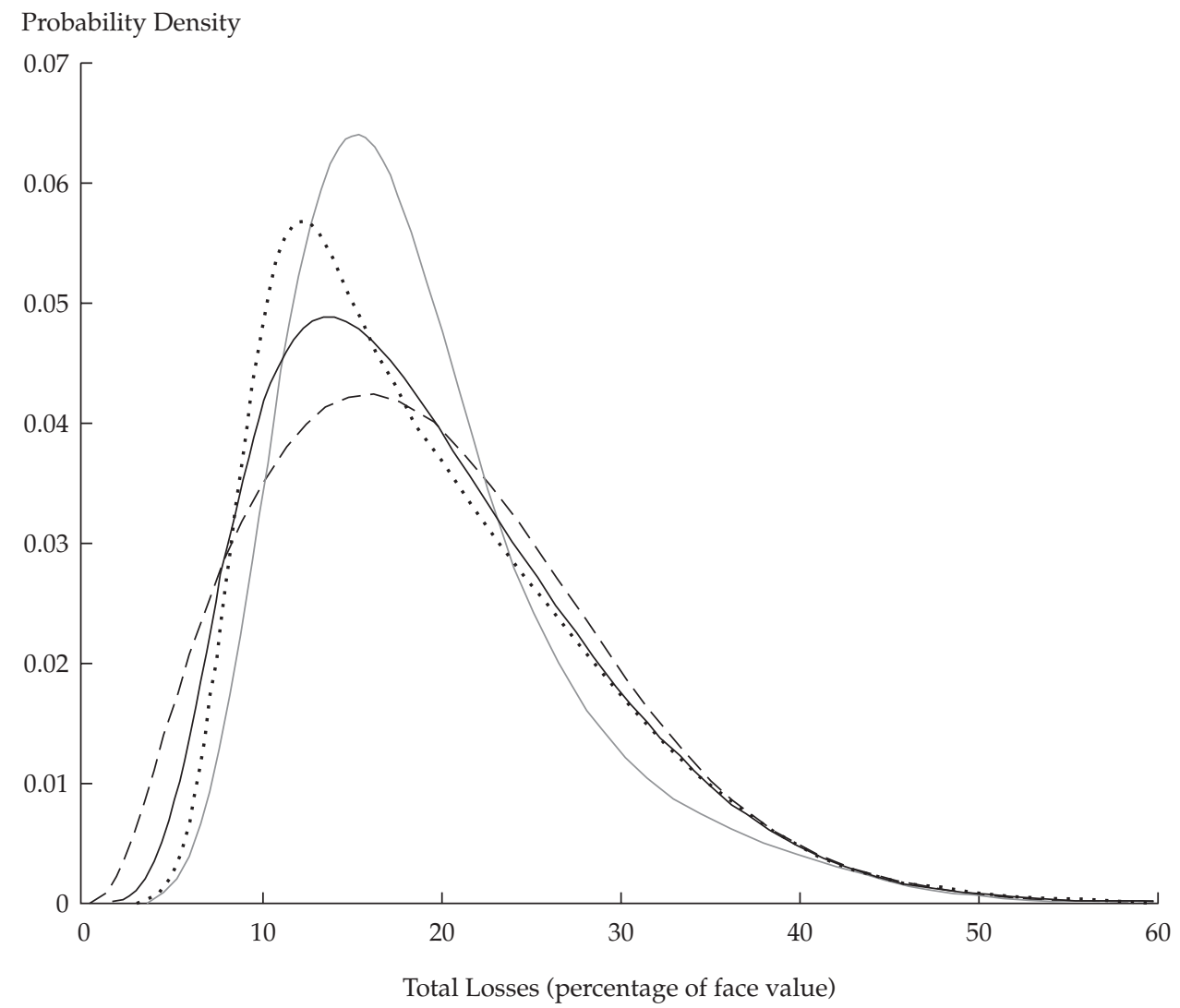

Set 1

$\ldots$ Set $2 \quad--\operatorname{Set} 4$

Figure 12. Spread Comparisons for Senior Tranches: High Correlation $(\rho=0.9)$, Low Subordination $\left(P_{1}=92.5\right)$

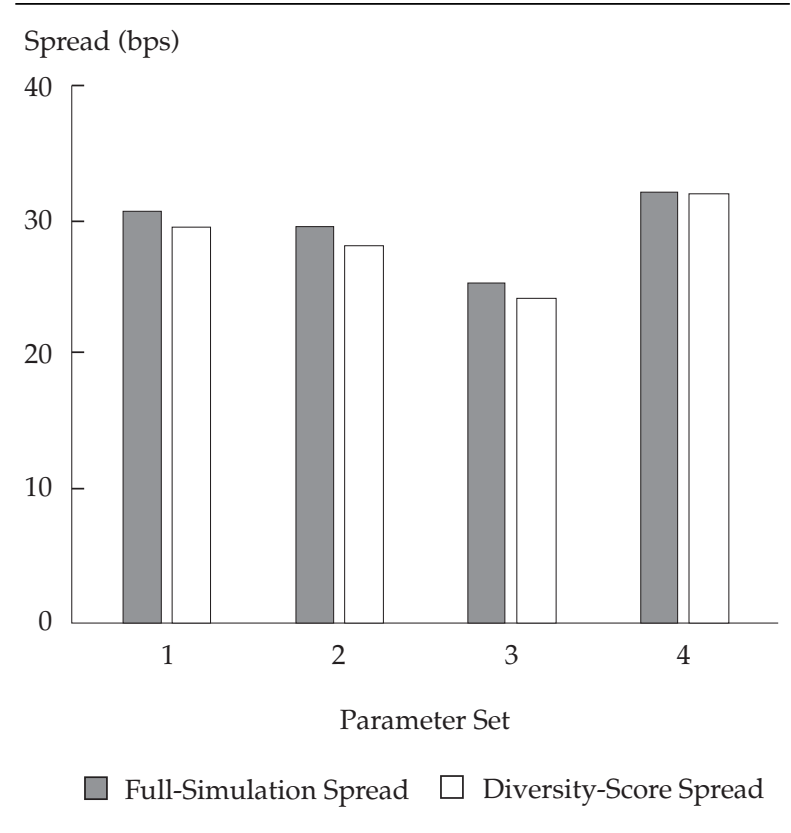

Figure 13. Spread Comparisons for Mezzanine Tranches: Moderate Correlation ( $\rho=0.5$ ), Low Subordination $\left(P_{1}=92.5, P_{2}=5\right)$

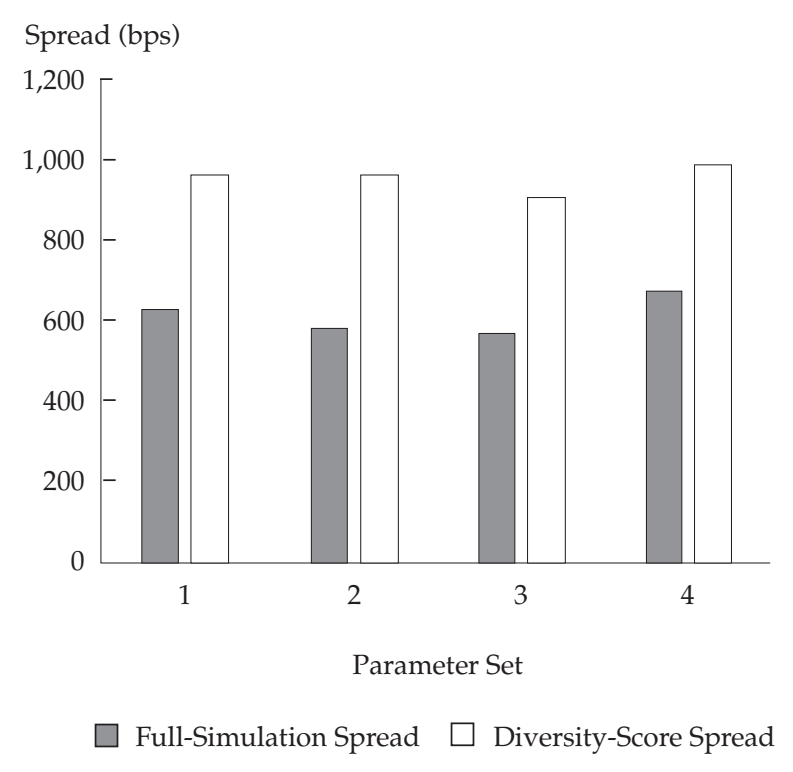


diversity-based spreads can be rather inaccurate, as can be seen in Figure 13.

Another source of approximation error from diversity-score-based calculations is concentration risk in the original portfolio. Suppose, for example, that the notional amount of one obligor is a large fraction of the total notional amount of the collateral pool. The hypothetical comparison portfolio, with equal notional amounts to each obligor, may have tail risk of default losses that is markedly smaller than the tail risk of the actual portfolio, despite having the same mean and variance of default losses. One might allow for concentration risk by construction of a comparison portfolio with similar concentration but still assuming no correlation of default losses.

Figure 15 shows the likelihood of a total loss of principal of at least 24.3 percent of the original face value as the correlation-determining parameter $\rho$ is varied. The figure also illustrates the calculation of the probability of failing to meet an overcollateralization target.

\section{Conclusions}

Default-time correlation has a significant impact on the market values of individual tranches. The priority of the senior tranche, by which it is effectively "short a call option" on the performance of the underlying collateral pool, causes its market value to decrease with the risk-neutral default-time correlation, fixing the (risk-neutral) distribution of individual default times. The value of the equity piece, which resembles a call option, increases with correlation. Intermediate tranches exhibit no clear Jensen effect. With sufficient overcollateralization, the option "written" (to the lower tranches) dominates, but it is the other way around for sufficiently low levels of overcollateralization.

Spreads, at least for mezzanine and senior tranches, are not especially sensitive to the "lumpiness" in the arrival of information about credit quality, in that replacing the contribution of diffusion with jump risks (of various types), while holding constant the degree of mean reversion and the term structure of credit spreads, plays a relatively small role in the determination of spreads.

Regarding alternative computational methods, if (risk-neutral) diversity scores can be evaluated accurately, which is computationally simple in the framework we proposed, these scores can be used to obtain good approximate market valuations for reasonably well-collateralized tranches.

Currently, the weakest link in the chain of $\mathrm{CDO}$ analysis is the availability of empirical data that would bear on the correlation, actual or risk neutral, of default.
Figure 14. Spread Comparisons for Mezzanine Tranches: Moderate Correlation ( $\rho=0.5)$, High Subordination $\left(P_{1}=80, P_{2}=10\right)$

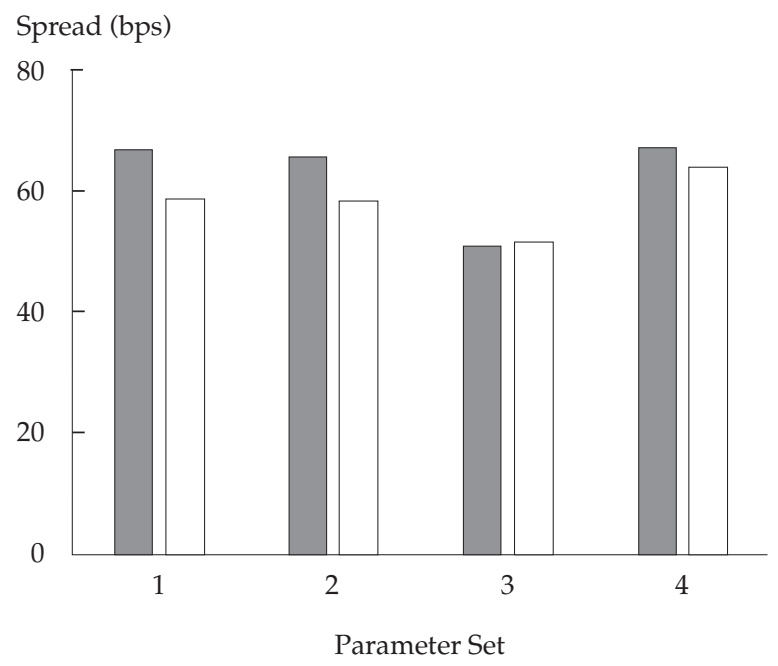

Full-Simulation Spread $\square$ Diversity-Score Spread
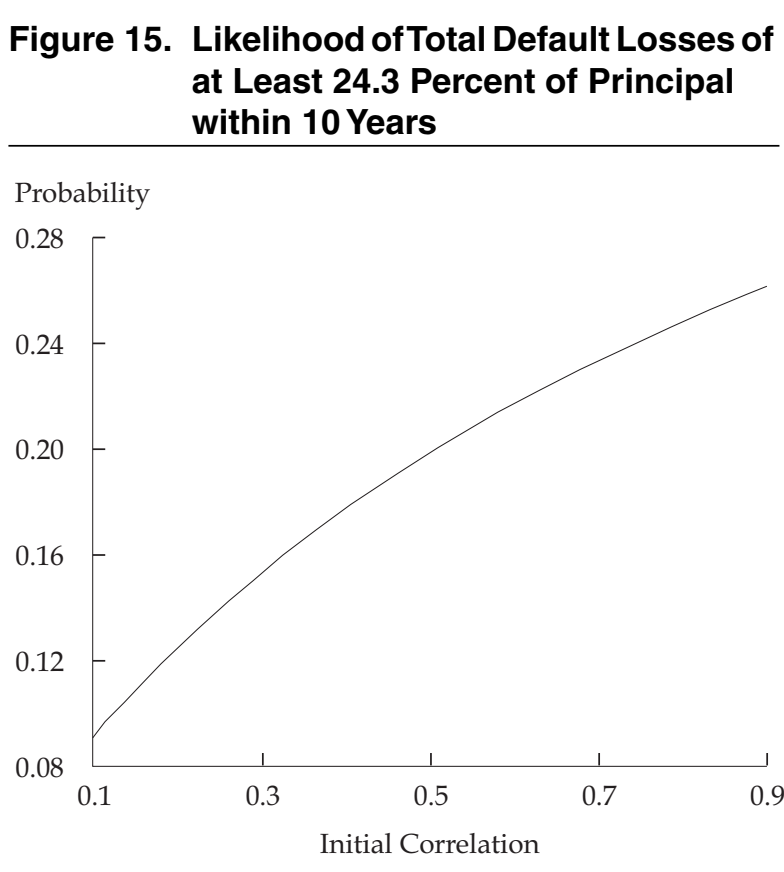

This work was supported in part by a grant from the Gifford Fong Associates Fund at the Graduate School of Business, Stanford University. We are grateful for discussions with Ken Singleton of Stanford University, Reza Bahar of Standard and Poor's, and Sergio Kostek of Morgan Stanley Dean Witter. Helpful comments and research assistance were provided by Jun Pan. We are also grateful for several helpful suggestions for improvement by Kazuhisa Uehara of the Fuji Research Institute Corporation. 


\section{Appendix A. Solution for the Basic Affine Model}

For the basic affine model, the expectation

$$
E\left\{\exp \left[\int_{0}^{s} q \lambda(t) d t\right] e^{v+u \lambda(s)}\right\}=e^{\alpha(s)+\beta(s)}
$$

is given by coefficient functions $\alpha(s)$ and $\beta(s)$ solving the following differential equations:

$$
\alpha_{s}^{\prime}=m \beta_{s}+\ell \frac{\mu \beta_{s}}{1-\mu \beta_{s}}
$$

and

$$
\beta_{s}^{\prime}=n \beta_{s}+\frac{1}{2} p \beta_{s}^{2}+q
$$

with the general boundary conditions $\alpha(0)=v$ and $\beta(0)=u$. The survival probability (Equation 4 ) is obtained as a special case, with $u=v=0, n=-\kappa$, $p=\sigma^{2}, q=-1$, and $m=\kappa \theta$. Barring degenerate cases, which may require separate treatment, the solutions are given by

$$
\begin{aligned}
\alpha_{s}= & v+\frac{m\left(a_{1} c_{1}-d_{1}\right)}{b_{1} c_{1} d_{1}} \log \frac{c_{1}+d_{1} e^{b_{1} s}}{c_{1}+d_{1}}+\left(\frac{m}{c_{1}}\right) s \\
& +\frac{\ell\left(a_{2} c_{2}-d_{2}\right)}{b_{2} c_{2} d_{2}} \log \frac{c_{2}+d_{2} e^{b_{2} s}}{c_{2} d_{2}}+\left(\frac{\ell}{c_{2}}-\ell\right) s
\end{aligned}
$$

and

$$
\beta_{s}=\frac{1+a_{1} e^{b_{1} s}}{c_{1}+d_{1} e^{b_{1} s}}
$$

where

$$
\begin{aligned}
& a_{1}=\left(d_{1}+c_{1}\right) u-1 \\
& b_{1}=\frac{d_{1}\left(n+2 q c_{1}\right)+a_{1}\left(n c_{1}+p\right)}{a_{1} c_{1}-d_{1}} \\
& c_{1}=\frac{-n+\sqrt{n^{2}-2 p q}}{2 q} \\
& d_{1}=\left(1-c_{1} u\right) \frac{n+p u+\sqrt{(n+p u)^{2}-p\left(p u^{2}+2 n u+2 q\right)}}{2 n u+p u^{2}+2 q} \\
& a_{2}=\frac{d_{1}}{c_{1}} \\
& b_{2}=b_{1} \\
& c_{2}=1-\frac{u}{c_{1}}
\end{aligned}
$$

$d_{2}=\frac{d_{1}-\mu a_{1}}{c_{1}}$

With these explicit solutions, we can compute the characteristic function $\varphi(\bullet)$ of $\lambda(s)$ given $\lambda(0)$, defined by

$$
\begin{aligned}
\varphi(z) & =E\left[e^{i z \lambda(s)}\right] \\
& =e^{\alpha(s)+\beta(s) \lambda(s)},
\end{aligned}
$$

by taking $q$ to equal zero and $u$ to equal $i z$ and treating the coefficients $\alpha(s)$ and $\beta(s)$ as complex. The Laplace transform $L(\bullet)$ of $\lambda(s)$ is computed analogously:

$$
\begin{aligned}
L(z) & =E\left[e^{-z \lambda(s)}\right] \\
& =e^{\alpha(s)+\beta(s) \lambda(s)} .
\end{aligned}
$$

In this case, we take $u=-z$. For details and extensions to a general affine jump diffusion setting, see Duffie, Pan, and Singleton (2000).

\section{Appendix B. Computation of Diversity Scores}

We define diversity score $S$ associated with a "target" portfolio of bonds of total principal $F$ to be the number of identically and independently defaulting bonds, each with principal $F / S$, whose total default losses have the same variance as the target portfolio's default losses. The computation of $S$ entails computation of the variance of losses on the target portfolio of $N$ bonds, which we address in this appendix.

For simplicity, we ignore any interest rate effects on losses in the calculation of diversity, although such effects could be tractably incorporated-by the discounting of losses, for example. (With correlation between interest rates and default losses, the meaningfulness of direct discounting is questionable.) Also, we do not separately consider lost-coupon effects in diversity scores. These effects, which could be particularly important for high-premium bonds, can be captured along the lines of the following calculations. Finally, diversity scores do not account directly for the replacement of defaulted collateral or new investment in defaultable securities during the life of a product, except insofar as covenants or ratings requirements stipulate a minimum diversity score that is to be maintained for the current collateral portfolio for the life of the CDO structure.

Letting $d_{i}$ denote the indicator of the event that participation $i$ defaults by a given time $T$ and letting $L_{i}$ denote the random loss of principal when this event occurs, the variance of total default losses is 


$$
\begin{aligned}
\operatorname{var}\left(\sum_{i=1}^{N} L_{i} d_{i}\right)= & E\left[\left(\sum_{i=1}^{N} L_{i} d_{i}\right)^{2}\right]-\left[E\left(\sum_{i=1}^{N} L_{i} d_{i}\right)\right]^{2} \\
= & \sum_{i=1}^{N} E\left(L_{i}^{2}\right) E\left(d_{i}^{2}\right) \\
& +\sum_{i \neq 1} E\left(L_{i} L_{j}\right) E\left(d_{i} d_{j}\right) \\
& -\sum_{i=1}^{N}\left[E\left(L_{i}\right)\right]^{2}\left[E\left(d_{i}\right)\right]^{2}
\end{aligned}
$$

Given an affine intensity model, one can compute all terms in Equation B1. In the symmetric case, letting $p_{(1)}$ denote the marginal probability of default of a bond and $p_{(2)}$ denote the joint probability of default of any two bonds, Equation B1 reduces to

$$
\begin{aligned}
\operatorname{var}\left(\sum_{i=1}^{N} L_{i} d_{i}\right)= & N p_{(1)} E\left(L_{i}^{2}\right) \\
& +N(N-1) p_{(2)}\left[E\left(L_{i}\right)\right]^{2} \\
& -N^{2} p_{(1)}^{2}\left[E\left(L_{i}\right)\right]^{2} .
\end{aligned}
$$

Equating the variance of the original pool to that of the comparison pool yields

$$
\begin{aligned}
\frac{N}{S}\left\{p_{(1)} E\left(L_{i}^{2}\right)-p_{(1)}^{2}\left[E\left(L_{i}\right)\right]^{2}\right\}= & p_{(1)} E\left(L_{i}^{2}\right) \\
& +(N-1) p_{(2)}\left[E\left(L_{i}\right)\right]^{2} \\
& -N p_{(1)}^{2}\left[E\left(L_{i}\right)\right]^{2} .
\end{aligned}
$$

Solving Equation B3 for the diversity score, $S$, one gets

$$
S=\frac{N\left\{p_{(1)} E\left(L_{1}^{2}\right)-p_{(1)}^{2}\left[E\left(L_{i}\right)\right]^{2}\right\}}{p_{(1)} E\left(L_{1}^{2}\right)+(N-1) p_{(2)}\left[E\left(L_{i}\right)\right]^{2}-N p_{(1)}^{2}\left[E\left(L_{i}\right)\right]^{2}} .
$$

To end the computation, one uses the identities $p_{(1)}=p_{1}$ and $p_{(2)}=2 p_{1}-p_{2}$, where $p_{1}$ and $p_{2}$ are computed according to Equation 28 in the text, and the fact that $E\left(L_{i}^{2}\right)=1 / 3$ and $\left[E\left(L_{i}\right)\right]^{2}=1 / 4$ if we assume losses are uniformly distributed on $(0,1)$. (Other assumptions about the distribution of $L_{i}$, even allowing for correlation here, can be accommodated.)

More generally, suppose $\lambda_{i}(t)=b_{i}[X(t)]$ and $\lambda_{j}(t)=b_{j}[X(t)]$, where $X$ is a multivariate affine process of the general type considered in Appendix $\mathrm{A}$ and $b_{i}$ and $b_{j}$ are coefficient vectors. Even in the absence of symmetry, for any times $t(i)$ and $t(j)$, assuming without loss of generality that $t(i) \leq t(j)$, the probability of default by $i$ before $t(i)$ and of $j$ before $t(j)$ is

$$
\begin{aligned}
E\left(d_{i} d_{j}\right)= & 1-E\left[e^{-\int_{0}^{t(i)} \lambda_{i}(u) d u}\right] \\
& -E\left[e^{-\int_{0}^{t(j)} \lambda_{j}(u) d u}\right] \\
& +E\left[e^{-\int_{0}^{t(j)} b(t) X(t) d u}\right],
\end{aligned}
$$

where $b(t)=b_{i}+b_{j}$ for $t<t(i)$ and $b(t)=b_{j}$ for $t(i) \leq t \leq t(j)$. Each of the terms in Equation B5 is analytically explicit in an affine setting, as can be gathered from Appendix A.

Beginning with Equation B5, the covariance of default losses between any pair of participations during any pair of respective time windows may be calculated, and from that result, the total variance of default losses on a portfolio and, finally, diversity score $S$ can be calculated. With lack of symmetry, however, one must take a stand on the definition of "average" default risk to be applied to each of the $S$ independently defaulting issues of the comparison portfolio. We do not address that issue here. A pragmatic decision could be based on further investigation, perhaps accompanied by additional empirical work.

\section{Notes}

1. A synthetic CLO differs from a conventional CLO in that for a synthetic CLO, the bank originating the loans does not actually transfer ownership of the loans to the SPV but, instead, uses credit derivatives to transfer the default risk to the SPV. A synthetic CLO may be preferred when the direct sale of loans to SPVs might compromise client relationships or secrecy or would be costly because of contractual restrictions on transferring the underlying loans.
Unfortunately, regulations do not always provide the same capital relief for a synthetic CLO as for a standard balance sheet CLO (see Punjabi and Tierney 1999).

2. This issue is related to the effects of adverse selection, but it also depends on the total size of the issue.

3. Supporting technical details are provided in the Duffie and Gârleanu 1999 working paper. 
4. An alternative would be a model in which simultaneous defaults could be caused by certain common credit events. An example is a multivariate exponential model (see Duffie and Singleton 1998). Another alternative is a contagion model, such as the static "infectious default" model of Davis and Lo (1999).

5. An affine interest-rate process is one in which zero-coupon yields are linear with respect to underlying state variables. For a more precise definition, see Duffie and Kan (1996).

6. A technical condition that is sufficient for the existence of a strictly positive solution to Equation 3 is that $\kappa \theta \geq \sigma^{2} / 2$. We do not require it because none of our results depends on strict positivity.

7. A proof can be found in the Duffie and Gârleanu 1999 working paper. The method of the proof is to verify that the Laplace transform of $X_{t}+Y_{t}$ is that of an affine process with initial condition $X_{0}+Y_{0}$ and parameters $(\kappa, \theta, \sigma, \mu, \ell)$.

8. Our model is "doubly stochastic," in the sense that, conditional on the processes $\lambda_{1}, \ldots, \lambda_{N}$, the default times $\tau_{1}, \ldots$, $\tau_{n}$ are independent and are the first jump times of counting processes with these respective intensities. Thus, the only source of default time correlation in our model is through correlation in the intensity processes.

9. A modeling alternative allowing for the treatment of correlated interest rate risk, and technical details, is in the 1999 Duffie and Gârleanu working paper.

10. This pricing approach was developed by Lando (1998) for slightly different default intensity models. Lando also allowed for correlation between interest rates and default intensity.

11. Moody's would not rely exclusively on the diversity score in rating $\mathrm{CDO}$ tranches.

12. That is, $B(k)$ is the subset of $A(k-1)$ that is not in $A(k)$.
13. Because all parameter sets have the same $\kappa$ parameter, maintaining the same term structure of zero-coupon yields was a rather straightforward numerical exercise, with Equation 4 used for risk-neutral default probabilities.

14. This calculation is based on the analytical methods described in the next section, "Analytical Results."

15. As a practical matter, if the investors' losses from default in the underlying collateral pool are sufficiently severe, Moody's may assign a "default" to a CDO tranche even if it meets its contractual payments.

16. The basis for this approach and other multi-obligor defaulttime simulation approaches is discussed in Duffie and Singleton (1998)

17. We use the convention that $\left(\begin{array}{c}m \\ \ell\end{array}\right)=0$ if $\ell<0$ or $m<\ell$.

18. We have not included the graphs in this article, but we note that low-correlation distributions are rather more similar across the various parameter sets than are high-correlation distributions. The full set of graphs is in the Duffie and Gârleanu 1999 working paper.

19. We are referring to the risk-neutral likelihood, unless the model under the objective probability is used.

20. For computation, we did not use the actual distribution of the total fractional loss of principal of a given number $k$ of defaulting participations. For ease of computation, we substituted with a central limit (normal) approximation for the distribution of the sum of $k$ identically and independently distributed uniform $(0,1)$ random variables, which is merely the distribution of a normally distributed variable with the same mean and variance. We were interested in this calculation for moderate to large levels of $x$, corresponding to, for example, estimating the probability of failure to meet an overcollateralization target. We have verified that, even for relatively few defaults, the central limit approximation is adequate for our purposes.

\section{References}

Akerlof, G. 1970. “The Market for 'Lemons': Qualitative Uncertainty and the Market Mechanism." Quarterly Journal of Economics, vol. 84, no. 3:488-500.

Cox, J.C., J. Ingersoll, and S. Ross. 1985. "A Theory of the Term Structure of Interest Rates." Econometrica, vol. 53, no. 2 (March):385-407.

Davis, M., and V. Lo. 1999. “Infectious Default.” Working paper, Research and Product Development, Tokyo-Mitsubishi International PLC.

DeMarzo, P. 1999. “Asset Sales and Security Design with Private Information." Working paper, Haas School of Business, University of California at Berkeley.

DeMarzo, P., and D. Duffie. 1999. "A Liquidity-Based Model of Security Design." Econometrica, vol. 67, no. 1:65-99.

Duffie, D., and N. Gârleanu. 1999. "Risk and Valuation of Collateralized Debt Obligations, Unabridged Version." Working paper, Graduate School of Business, Stanford University (www.Stanford.edu/ duffie/working.htm).

Duffie, D., and R. Kan. 1996. "A Yield Factor Model of Interest Rates." Mathematical Finance, vol. 6, no. 4 (October):379-406.

Duffie, D., and K. Singleton. 1998. "Simulating Correlated Defaults." Working paper, Graduate School of Business, Stanford University.
- 1999. "Modeling Term Structures of Defaultable Bonds." Review of Financial Studies, vol. 12, no. 4 (Special):687720 .

Duffie, D., J. Pan, and K. Singleton. 2000. "Transform Analysis and Asset Pricing for Affine Jump Diffusions." Econometrica, vol. 68, no. 6 (November): 1343-76.

Feller, W. 1951. "Two Singular Diffusion Problems." Annals of Mathematics, vol. 54, no. 1:173-182.

Innes, R. 1990. "Limited Liability and Incentive Contracting with Ex-Ante Choices." Journal of Economic Theory, vol. 52, no. 1:45-67.

Lando, D. 1998. "On Cox Processes and Credit-Risky Securities." Review of Derivatives Research, vol. 2, nos. 2-3:99-120.

Punjabi, S., and J. Tierney. 1999. "Synthetic CLOs and Their Role in Bank Balance Sheet Management." Working paper, Fixed Income Research, Deutsche Bank.

Schorin, C., and S. Weinreich. 1998. "Collateralized Debt Obligation Handbook." Working paper, Fixed Income Research, Morgan Stanley Dean Witter. 